\title{
Electron Microscopic Analysis of D1 and D2 Dopamine Receptor Proteins in the Dorsal Striatum and Their Synaptic Relationships with Motor Corticostriatal Afferents
}

\author{
Steven M. Hersch, ${ }^{1}$ Brian J. Ciliax, ${ }^{1}$ Claire-Anne Gutekunst, ${ }^{1}$ Howard D. Rees, ${ }^{1}$ Craig J. Heilman, ${ }^{1}$ Ken K. L. \\ Yung, ${ }^{2}$ J. Paul Bolam, ${ }^{2}$ Ernesto Ince, ${ }^{1}$ Hong $\mathrm{Yi}^{1}{ }^{1}$ and Allan I. Levey ${ }^{1}$ \\ ${ }^{1}$ Department of Neurology, Emory University School of Medicine, Atlanta, Georgia 30322 and ${ }^{2}$ MRC Anatomical \\ Neuropharmacology Unit, Oxford, United Kingdom
}

The precise localization of D1 and D2 dopamine receptors within striatal neurons and circuits is crucial information for further understanding dopamine pharmacology. We have used subtype specific polyclonal and monoclonal antibodies against D1 and D2 dopamine receptors to determine their cellular and subcellular distributions, their colocalization, and their differential connectivity with motor cortical afferents labeled either by lesion-induced degeneration or by anterograde transport of biotinylated dextrans. D1 and D2 are primarily expressed in medium-sized neurons and spiny dendrites. Axon terminals containing D1 were rare whereas D2-immunoreactive axon terminals forming symmetrical synapses with dendrites and spines were common. In $2 \mu \mathrm{m}$ sections, D1 was localized to $53 \%$ of neurons, and D2 to $48 \%$ of neurons, while mixing D1 and D2 antibodies labeled $78 \%$. By electron microscopy, D1 was localized to $43 \%$ of dendrites and $38 \%$ of spines while D2 was localized to $38 \%$ of dendrites and $48 \%$ of spines. Combining D1 and D2 antibodies resulted in the labeling of $88.5 \%$ of dendrites and $92.6 \%$ of spines. Using different chromogens for D1 and D2, colocalization was not observed. Ipsilateral motor corticostriatal afferents were primarily axospinous and significantly more synapsed with D1 than D2-positive spines ( $65 \%$ vs $47 \%$ ). Contralateral motor corticostriatal afferents were frequently axodendritic and no difference in their frequency of synapses with D1 and D2 dendrites and spines was observed. These findings demonstrate differential patterns of expression of D1 and D2 receptors in striatal neurons and axon terminals and their differential involvement in motor corticostriatal circuits.

[Key words: D1, D2, dopamine receptors, striatum, basal ganglia, corticostriatal, motor cortex, rat]

Dopamine is involved in complex pre- and postsynaptic interactions in the striatum where it plays a key role in basal ganglia function and in pathologic conditions including Parkinson's dis-

\footnotetext{
Reccived Sept. 22, 1994; revised Гieb. 1, 1995; Feb. 27, 1995.

This work was supported by the U.S. Public Health Service (NS01624, NS31937), an American Parkinson's Disease Association Research Center Grant, and The Stanley Foundation.

Correspondence should be addressed to Steven M. Hersch, M.D. Ph.D. Department of Neurology, Emory University School of Medicine, Woodruff Memorial Building, Suite 6000, Atlanta, GA 30322.

Copyright 1995 Society for Neuroscience $0270-6474 / 95 / 155222-16 \$ 05.00 / 0$
}

ease, Iluntington's disease, and schizophrenia. Dopamine is released in the striatum by nigrostriatal afferents where it acts upon dopamine receptors with differing hiochemical activities and differing distributions. D1 and D2 dopamine receptor subtypes have been distinguished on pharmacologic, physiologic, and anatomic grounds. However, molecular cloning experiments have uncovered at least five distinct genes coding for individual dopamine receptors (D1-D5). Molecular D1 and D5 receptors constitute the D1 subfamily (high affinities for benzazepines and activation of adenylate cyclase) while molecular D2, D3, and D4 constitute the D2 subfamily (high affinity for butyrophenones and substituted benzamides, inhibition or no effect on adenylate cyclase). The precise cellular and subcellular location of these receptor subtypes critically determines how each is involved in striatal functioning, what afferent and efferent pathways they mediate, and how subtype selective pharmacologic agents may function.

The cellular localization of mRNA for dopamine receptors in the striatum has been studied by in situ hybridization (Mengod et al., 1989; Dearry et al., 1990; Weiner et al., 1990; Chen et al., 1991; Fremeau et al., 1991; Le Moine et al., 1991; Weiner et al., 1991; Lester et al., 1993). D1 and D2 mRNA are each found in about $45 \%$ of striatal neurons (Weiner et al., 1991; Gerfen, 1993). Each is primarily found in medium sized neurons; however, D2 is also found in large striatal cholinergic interncurons (Le Moine et al., 1990). The two receptor subtypes appear to be expressed by distinct populations of neurons (Le Moine et al., 1991; Gerfen, 1993) with substance $P$ and dynorphin expressing striatonigral neurons containing D1, and enkephalinergic striatopallidal neurons containing D2 (Gerfen et al., 1990). However, other investigators have suggested that a third or more of striatal neurons express both D1 and D2 receptors (Meador-Woodruff et al., 1991; Lester et al., 1993). Amplification of mRNA for dopamine receptors from single striatal neurons has even suggested that the vast majority express both D1 and D2 (Surmeier et al., 1992). However, mRNA abundance may not accurately reflect the quantity of functional receptor and it remains controversial to what extent D1 and D2 are expressed in the same neurons (Surmeier et al., 1993).

Localization of receptor subtypes using specific antibodies provides a more direct means of studying receptor expression. Several laboratories have made antibodies against peptides from either D1 or D2 and used them for immunohistochemistry. Huang and colleagues localized D1 in $49 \%$ of striatal neurons and in spiny dendrites (Huang et al., 1992). However, the selec- 
tivity of their antibody was not well established. Others have developed D2 peptide antibodies (McVittie et al., 1991; Ariano et al., 1992; Ariano et al., 1993; Boundy et al., 1993; Sesack et al., 1994) and demonstrated their expression in $50 \%$ of striatal neurons (McVittie et al., 1991). However, D2 was also found in the majority of striatonigral neurons (Ariano et al., 1992) suggesting it to be expressed by both major output populations. None of these investigations were able to directly compare D1 and D2 localization in the same animals and none have compared the synaptic relationships of D1 and D2 processes with extrinsic striatal afferents.

We have previously described the development and characterization of polyclonal fusion protein antibodies for D1 and D2 receptors (Levey et al., 1993; Ciliax et al., 1994). We now report using these antibodies and a new monoclonal Dl antibody to localize these receptors in specific striatal neurons and processes; to quantify their expression in striatal neurons, dendrites, and spines; to determine whether they are colocalized in individual striatal neurons and to compare their synaptic relationships with identified motor cortical afferents.

\section{Materials and Methods}

Antibodies. The preparation and characterization of rabbit polyclonal antibodies specific for D1 and D2 dopamine receptors have been previously described (Levey et al., 1993). Briefly, these antibodies were raised against proteins, fused to glutathione S-transferase, that had been derived from the putative C-terminus of D1 and the third inner cytoplasmic loop (i3) of D2 (short isoform). The selected regions of each respective receptor have little or no sequence homology (with each other, with D3, D4, or D5, or with other related families of receptors). Antibodies used in the present study were affinity purified using the respective fusion proteins. Each antisera immunoprecipitates its respective cloned and expressed receptor without cross reaction. The D2 antibodies recognize both the short and long splice variants of this receptor. In addition, distribution of the native receptor proteins in rat brain is similar both by immunoprecipitation and immunocytochemistry, and antibody binding is blocked in these assays by addition of the homologous fusion protein. Also, the cellular localization of the receptor proteins in brain is in excellent agreement with the localization of their respective mRNAs. Finally, Western blotting studies have demonstrated that the antibodies bind to the cloned and native receptors with complete specificity. These data rigorously establish the subtype specificity of the antibodies.

A hybridoma cell line was generated that secretes a monoclonal anlibody reactive with $\mathrm{D} 1$. The hybridoma was produced by fusion of rat spleen cells with murine nonsecreting myeloma cell line $\mathrm{Sp} 2 / 0$, as previously described (Levey et al., 1983). Briefly, a male Sprague-Dawley rat was immunized over a 4 month period with repeated intradermal and intraperitoneal injections of D1-C terminus protein fused genetically to glutathione, GST (D1C-GST, $100 \mu \mathrm{g}$ ) (Levey et al., 1993). Three days following a final intravenous boost, the spleen was harvested and lymphoid cells were isolated by centrifugation through Ficollpaque. Splenocytes were fused with myeloma cells at a 5:1 ratio using $50 \%$ polyethylene glycol 1500 , and then plated in selection media (DMEM, 20\% fetal clone, $2 \mathrm{mM}$ L-glutamine, $50 \mathrm{I} . \mathrm{U} . / \mathrm{ml}$ penicillin, 50 $\mu \mathrm{g} / \mathrm{ml}$ streptomycin, $0.1 \mathrm{~mm}$ hypoxathine, $0.0004 \mathrm{~mm}$ aminopterin, $0.016 \mathrm{~mm}$ thymidine) to a final concentration of $500,000 \mathrm{cells} / \mathrm{ml}$ in 96 well microtiter plates. Hybridomas were screened by immunoblotting using D1C-GST and GST, and then verified by immunoblotting using the full length expressed receptor as well as by immunocytochemistry. A single hybridoma cell line was isolated following repeated cloning at limiting dilutions. Culture supernatants were concentrated by ammonium sulfate precipitation and dialyzed into Tris-EDTA buffer.

Gel electrophoresis and immunoblotting. Western blotting studies were performed to further characterize the specificity of the antibodies. Membranes from COS-7 cell lines stably expressing D1-D5 dopamine receptor cDNAs or rat brain regions were prepared as described previously (Levey et al., 1993). Samples (50 $\mu \mathrm{g}$ from rat brain, $5 \mu \mathrm{g}$ from cell lines) were subjected to SDS-polyacrylamide gel electrophoresis (SDS-PAGE with $10 \%$ acrylamide) and transferred to Immobilon membranes by electroblotting (150 mA, overnight) as described by Towbin
(Towbin et al., 1979). The blots were blocked in 5\% nonfat dried milk at room temperature for $1 \mathrm{hr}$, and then incubated with affinity-purified antibodies $(0.5-1.0 \mu \mathrm{g} / \mathrm{ml})$ diluted in blocking buffer at $4^{\circ} \mathrm{C}$ overnight. After washing with several changes of TBS, blots were incubated with horseradish peroxidase-conjugated goat anti-rabbit immunoglobulin $G$ (1:10,000, Bio-Rad) for 1 hr. After several washes, immunoreactive proteins were visualized on the blots using enhanced chemiluminescence (ECL, Amersham) as recommended by the manufacturer, using Hyperfilm-ECL (Amersham) and exposure times of 1-120 min.

Subjects and conditions. A total of 30 young adult male SpragueDawley (Harlan) rats were used in immunoelectron microscopy experiments. Eighteen rats did not undergo any experimental procedures. Four rats had cortical lesions in one hemisphere. Four rats had anterograde tracer injections in one hemisphere. Four rats had cortical lesions on one side and tracer injections on the opposite side.

The following types of striatal sections were analyzed by light and electron microscopy, D1 or D2 immunocytochemistry in animals without cortical lesions or injections, D1 combined with D2 in the same sections using the same or different chromogens, cortical lesions or injections without dopamine receptor immunocytochemistry, D1 or D2 immunocytochemistry ipsilateral to cortical lesions or injections, DI or D2 immunocytochemistry ipsilateral to cortical lesions and contralateral to cortical injections of biotinylated dextrans (BD), immunocytochemical controls processed in parallel but without exposure to the printary antibody. Blocks from at least two sections for each condition from each animal were examined by electron microscopy.

Surgical procedures. Rats undergoing surgical procedures were anesthetized with $7.0 \%$ chloral hydrate injected intraperitoneally. The scalp was incised and a parasagittal strip of skull was removed overlying the frontal lobe, exposing the primary motor cortical regions (areas Fr1, Fr3, FL, HL; Paxinos and Watson, 1986). Lesions of motor cortex, performed by aspiration through a modified Pasteur pipette, included the entire thickness of cortical gray matter and had a rostrocaudal extent of about bregma plus $4.2 \mathrm{~mm}$ at lateral $3.0 \mathrm{~mm}$ to bregma minus 0.8 $\mathrm{mm}$ at lateral $2.0 \mathrm{~mm}$. For anterograde tracing, a $10 \%$ aqueous solution of 10,000 molecular weight, lysine fixable, biotinylated dextrans (BD, Molecular Probes) was used. Injections were made through a glass micropipette with a fitted wire acting as a plunger according to the following sequence: the pipette was slowly introduced, a 5 min delay allowed equilibration, an injection was made over $10 \mathrm{~min}$. another 5 min delay to permit spread of the tracer into the surrounding brain, then the pipette was slowly withdrawn. Injected hemispheres received three pressure injections of $250 \mathrm{nl}$. Injections were targeted at layer $\mathrm{V}$, spanned multiple layers but did not enter the subcortical white matter. Rats receiving an aspiration lesion had a $4 \mathrm{~d}$ survival period. Rats receiving BD injections had a $10-12$ d survival period. Rats receiving both had unilateral $\mathrm{BD}$ injections on day 1 , a contralateral lesion on day 7 , and perfusion on day 11

Histology. The rats were deeply anesthetized with chloral hydrate and perfused transcardially with $240 \mathrm{ml}$ of $3 \%$ paraformaldehyde and $0.1-$

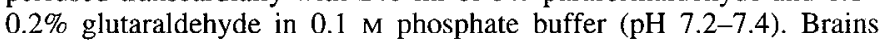
were removed $1 \mathrm{hr}$ after perfusion and sectioned at $40 \mu \mathrm{m}$ using a vibratome (Technical Products International). Sections were collected in $0.1 \mathrm{M}$ phosphate buffered saline (PBS) and rinsed in $0.05 \mathrm{M}$ Tris buffered saline (TBS, pH 7.2) for $10 \mathrm{~min}$. Free-floating sections were preblocked for $1 \mathrm{hr}$ in $4 \%$ normal goat serum (NGS) in TBS then subjected to one of several immunocytochemical procedures, as detailed below.

Some sections from each animal and condition were mounted on glass slides and saved for light microscopic examination. For electron microscopy, the motor regions of the caudate-putamen (as determined by $\mathrm{BD}$ anterograde tracing) were dissected free of the cortex and ventral forebrain, rinsed in $0.1 \mathrm{M}$ cacodylate buffer twice for $10 \mathrm{~min}$, then postfixed in $1 \%$ osmium tetroxide in cacodylate buffer for $30 \mathrm{~min}$. After rinsing the sections for $10 \mathrm{~min}$ in two changes of cacodylate buffer, and for $10 \mathrm{~min}$ in two changes of $0.05 \mathrm{M}$ acetate buffer, they were stained overnight in $2-5 \%$ aqueous uranyl acetate. Sections were again rinsed in acetate buffer, dehydrated in graded alcohols, then in propylene oxide for 5 min before being embedded in Durcupan resin (Fluka) between glass slides. Blocks were dissected from the dorsolateral striatum, mounted on plastic stubs, and sectioned using an ultramicrotome (RMC MT5000 or Reichert Ultracut). When present, BD labeled axons provided a visual guide for block selection. One micrometer sections were taken, mounted on glass slides, and stained with toluidine blue for light microscopic examination. Silver ultrathin sections were collected on 
mesh or slotted copper grids and left unstained for electron microscopy (Zeiss EM10) to avoid the production of confounding staining artifact.

To determine the relative numbers of neuronal somata labeled in the dorsolateral striatum with each dopamine receptor protein antibody, counts were made of labeled and unlabeled somata in 1-2 $\mu \mathrm{m}$ thick plastic sections, counterstained with toluidine blue. These were accomplished using a $60 \times$ oil immersion lens mounted on a Nikon FXA microscope. For each antibody, between 800 and 900 neurons, sectioned through their nuclei, were counted in single sections from multiple tissue blocks from two brains with the intense immunostaining. Counts were made from sections immunostained to reveal D1, D2, and D1 combined with D2.

Immunocytochemistry. The following procedure was used for the animals, with or without lesions and injections, in which light and electron microscopic quantification was performed. The sections to be stained using affinity purified polyclonal primary antibody were prehlocked with avidin $(10 \mu \mathrm{g} / \mathrm{ml})$ in $4 \%$ normal goat serum in TBS (NGS-TBS) for $30 \mathrm{~min}$ followed by TBS rinses for $30 \mathrm{~min}$. Sections to be stained with monoclonal D1 antibody were preblocked with $4 \%$ NGS. Scetions were then incubated at $4^{\circ} \mathrm{C}$ on a shaker platform for $48 \mathrm{hr}$ in polyclonal D1 or D2 $(2 \mu \mathrm{g} / \mathrm{ml})$, monoclonal D1 (1:500), or a mixture of monoclonal D1 and polyclonal D2 antibodies in $2 \%$ NGS-TBS (primary antibody omitted for control sections). Sections were then rinsed in six changes of cold TBS for a total of $1 \mathrm{hr}$, then incubated overnight in either biotinylated goat-anti rabbit secondary antibody (1:200, Vector ABC Elite) in TBS with 2\% NGS for polyclonal primary, goat antimouse $(1: 200)$ for monoclonal D1, or a mixture of both secondary antibodies. After rinsing in six changes of TBS for a total of $1 \mathrm{hr}$, the sections were incubated for $4 \mathrm{hr}$ in avidin-biotin complex (Vector $\mathrm{ABC}$ Elite), mouse peroxidase-antiperoxidase (1:200, Sternberger Monoclon als), or a mixture of both tertiary complexes. After further rinses with TBS, final development was with $0.05 \%$ 3-3'-diaminobenzidine tetrahydrochloride (DAB, Sigma) and $0.01 \%$ hydrogen peroxide in TBS for 10-20 min. Sections were then rinsed with TBS for another hour. For those animals with $\mathrm{BD}$ injections, this procedure revealed both the $\mathrm{BD}$ containing axons and D1 or D2 immunoreactive neurons.

$D 1$ and $D 2$ double labeling. The following procedures were followed to determine whether D1 and D2 receptor immunoreactivity could be detected in the same neurons or neuronal processes. Sections from four rats were washed in three changes of PBS, equilibrated in $25 \%$ sucrose and $10 \%$ glycerol in $0.05 \mathrm{M}$ phosphate buffer (PB), and freeze-thawed in isopentane and liquid nitrogen. The sections were preblocked with $4 \%$ normal serum and immunostained using two different chromogens to reveal the immunoreactivity for the D1 and D2 dopamine receptors on the same section. In the first two animals, the primary antibodies were applied in sequence. In the third and fourth animals, the two primary antibodies were mixed together. All incubations were at room temperature.

For the first two animals, the sections were first incubated in polyclonal D2 antibody (1:100 in PBS with 2\% normal goat serum) for 24 hr. The sections were then washed in three changes of PBS and incubated in biotinylated goat anti-rabhit secondary antibody (1:100 Vector) for $2 \mathrm{hr}$. Following further rinses in PBS, they were incubated in avidinbiotin complex (1:100, ABC kit, Vector) for $1 \mathrm{hr}$, washed in PBS followed by Tris- $\mathrm{HCl}$, and then developed with $\mathrm{DAB}$ containing $0.0048 \%$ $\mathrm{H}_{2} \mathrm{O}_{2}$ for 5-10 min. The reaction was stopped by several washes in Tris buffer followed by PBS. The sections were then incubated in D1 monoclonal antibody, (1:1000 in PBS with $2 \%$ normal goat serum) at RT for $24 \mathrm{hr}$, biotinylated goat anti-rat secondary antibody solution $(1: 100$, Vector) for $2 \mathrm{hr}$ and the avidin-biotin-peroxidase method was repeated. However D1 receptor immunoreactivity was revealed using the chromogen benzidine dihydrochloride (BDHC, $0.01 \%$, in $0.01 \mathrm{M} \mathrm{PB}, \mathrm{pH}$ 6.8 with $0.0025 \%$ sodium nitroprusside and $0.0048 \% \mathrm{H}_{2} \mathrm{O}_{2}$ ) (Levey et al., 1986). In some sections the D1 immunoreactivity was revealed using the Vector SG kit as substrate for the peroxidase reaction.

In the third and fourth animal, the primary antibodies were applied as a mixture (monoclonal D1, 1:2000; polyclonal D2, 1:50 in PBS with normal goat serum) and incubated for $24 \mathrm{hr}$. Sections from the third animal were then washed in PBS, and incubated in the first secondary antibody solution (biotinylated goat anti-rabbit, 1:100, Vector) for $2 \mathrm{hr}$, rinsed in three changes of PBS, and then incubated in avidin-biotin complex (Vector $\mathrm{ABC}$ kit) for $1 \mathrm{hr}$. D2 immunoreactivity was then revealed using the $\mathrm{DAB}$ procedure. After this reaction, the sections were rinsed and incubated in the second secondary antibody (biotinylated goat anti-rat, 1:100, Vector) for $2 \mathrm{hr}$, rinsed, and again incubated in avidin-biotin complex (Vector, $\mathrm{ABC}$ kit) for 1 hr. D1 immunoreactivity was then revealed using the BDHC procedure. For the fourth animal, both secondary antibodies were applied as a mixture (biotinylated goat anti-rabbit, 1:100 and goat anti-rat, 1:100) for $2 \mathrm{hr}$. The sections were then rinsed and incubated in avidin-biotin complex (Vector) for an hour. D2 immunoreactivity was revealed using the DAB procedure. The sections were then incubated in rat peroxidase-antiperoxidase complex (PAP) for another hour and D1 immunoreactivity was revealed by using BDHC as chromogen.

Quantitative electron microscopy. For quantitative analysis of dopamine receptor labeling and presynaptic corticostriatal terminals, 8-10 overlapping electron micrographs, photographed at an original magnification of either $6000 \times$ or $7000 \times$ and printed at a final magnification of $19,600 \times$, constituted the sampling region for each block. Each sampling region was from the dorsolateral caudate-putamen and was positioned to avoid bundles of myelinated axons. No distinction was made between darker and lighter staining regions and sections for quantification were all taken the surface of their respective blocks. These prints were montaged and counts made of all labeled and unlabeled dendritic processes, all labeled and unlabeled dendritic spines that had identifiable synapses, and (when present) all degenerating or BD labeled axon terminals forming identifiable synapses. Axon terminals and dendritic spines not forming synapses were not counted. Spine profiles receiving symmetrical synapses only were also excluded. Dendrites, spines, and axon terminals were identified based upon well known morphological criteria (Peters et al., 1976). All counts were performed by the first author who was blinded to the identity of the dopamine receptor antibody.

\section{Results}

\section{Specificity of D1 monoclonal antibody}

The D1 rat monoclonal antibody binds only to the D1C-GST fusion protein on Western blots, without cross-reactivity to GST or other dopamine receptor fusion proteins (not shown). It recognizes protein from celis transfected with the D1 cDNA, but not from cells transfected with the closely related D5 cDNA, or D2, D3, and D4, cDNAs (Fig. 1). D1 immunoreactive proteins show a broad range of sizes in transfected cells, which may occur due to varying lengths of the translation products (e.g., alternate start sites or early termination), varying degrees of glycosylation, aggregation, and/or proteolysis (Deutscher, 1990). However, the major bands of D1 immunoreactivity are at 40-45 $\mathrm{kDa}$ and $65-75 \mathrm{kDa}$, corresponding to the size predicted by the primary sequence and biochemical studies for the deglycosylated and glycosylated forms of the core protein (Jarvie et al., 1989). In rat brain membranes, the antibody binds to a single protein band at approximately $65-75 \mathrm{kDa}$, which is the same mohility as the cloned D1 receptor (Fig. 1). The distribution of the D1 immunoreactivity on blots is enriched in striatum, with much less immunoreactivity in other brain regions. The immunocytochemical distribution of D1 immunoreactivity in rat brain using the monoclonal antibody appears identical to the distribution using the polyclonal antibodies previously described (Levey et al., 1993). Moreover, the subcellular distribution of D1 immunoreactivity in rat striatum in the electron microscopic studies reported here was identical using either the monoclonal or the polyclonal antibody.

\section{Control immunocytochemistry}

Control sections from each brain, processed without exposure to primary antibody, were examined by light microscopy. In each case, labeling of neurons, neuronal processes, or glia were not observed. By electron microscopy, no DAB reaction product was observed in the caudate-putamen in neuronal somata, dendrites, or axons. However, occasional myelin sheaths appeared to be labeled with reaction product. In cases with cortical $\mathrm{BD}$ injections, no DAB labeling was present in postsynaptic pro- 


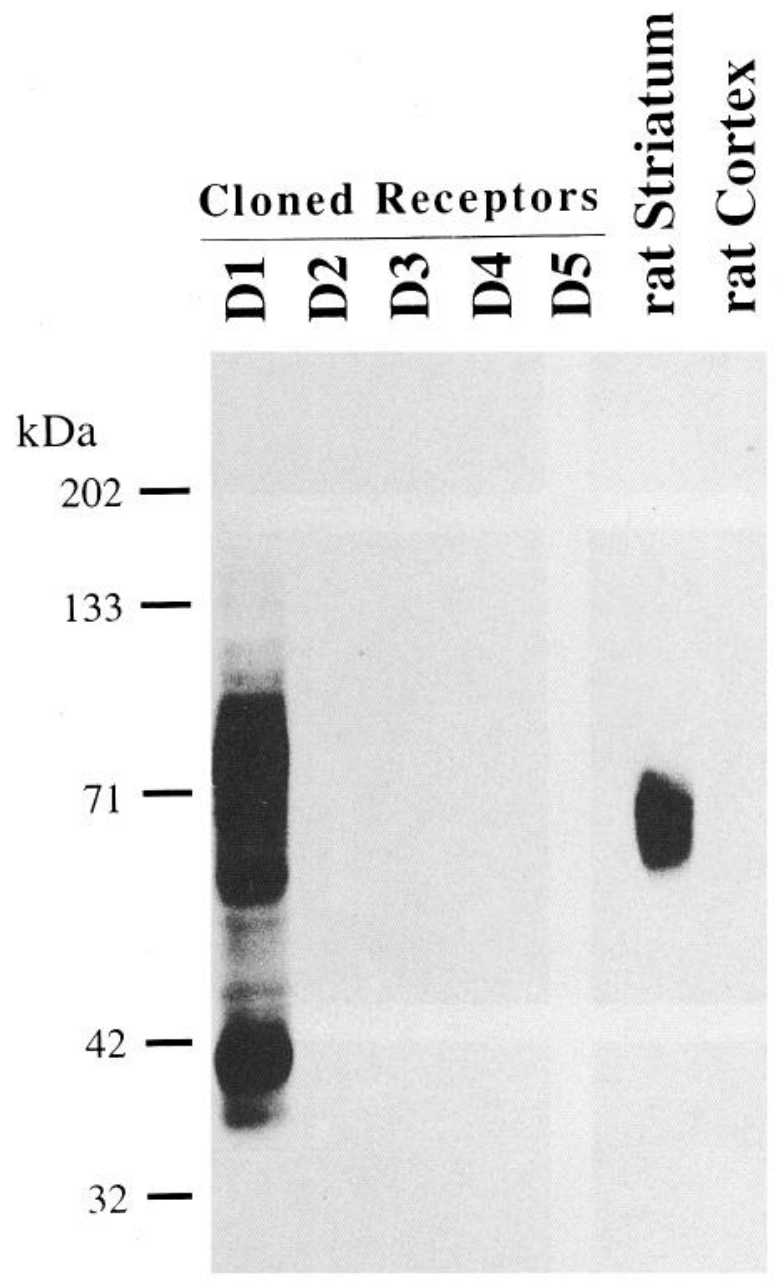

Figure 1. Western blot demonstrating the specificity of the monoclonal D1 antibody. Aliquots $(\mu \mathrm{g})$ of membranes were prepared, subjected to SDS-PAGE, and immunoblotted. The first five lanes contain membranes from transfected cell lines individually expressing D1-D5 receptors. The monoclonal D1 antibody is monospecific for D1 without cross-reaction with D2-D5. The wide molecular weight range visualized in the first lane is due to the variable translation of receptor protein commonly observed in various expression systems. The last two lanes, containing membranes from rat striatum and cerebral cortex, demonstrate the expected regional specificity of D1.

cesses. In cases with cortical lesions, degenerating axons and axon terminals were evident. Dark terminals that might be counted as degenerating were exceedingly rare in cases without lesions.

\section{D1 and D2 receptor immunocytochemistry - light microscopy}

The light microscopic appearance of D1 and D2 immunocytochemistry in the striatum has been described previously (Levey et al., 1993; Yung et al., 1994). By light microscopy, they were very similar, each with dense and heterogeneous staining of striatal neurons and neuropil (Fig. 2). In neighboring sections stained for D1 and D2, the heterogeneity was only partially complementary and commonly not of a scale consistent with patch/ matrix markers. When individual sections were simultaneously stained for both D1 and D2 (Fig. 2), there was much denser staining, but still much heterogeneity was observed. When separate chromogens were used, D1 and D2 immunoreaction product could be distinguished by their difference in color (blue
BDHC reaction product for D1 and brown DAB reaction product for D2). They appeared to be located in different structures with dense brown D2 immunoreactive structures often appearing to be surrounded by more discrete blue D1-immunoreactive structures. Following osmication, however, it was no longer possible to clearly distinguish the two reaction products by color because they both became so dark. Individual neuronal perikarya were visible (Fig. 2), but were often obscured by the dense neuropil staining. In $1-2 \mu \mathrm{m}$ thick plastic sections (Fig. 2), stained and unstained perikarya were easier to distinguish and the neuropil staining could be resolved to a multitude of fine processes. Counts were made of labeled and unlabeled neurons in each condition. Following D1 immunocytochemistry, 53\% of neurons were labeled $(n=1018, \mathrm{SD}=6.0 \%)$; following D2 immunocytochemistry $48 \%$ of neurons were labeled $(n=1189, \mathrm{SD}=$ $3.2 \%)$; following combined D1 and D2 staining 78\% $(n=708$, $\mathrm{SD}=7.6 \%$ ).

\section{D1 and D2 receptor immunocytochemistry-electron microscopy}

By electron microscopy, most labeled neuronal somata conformed cytologically to medium spiny neurons (Figs. $3 A, 4 A$ ), being small to medium in size with a round to oval nucleus without folds, a modest amount of cytoplasm and sparse somatic synapses (Fig. 4C). In D2 immunostained sections, larger oval neurons with rich cytoplasm and nuclei with membrane folds were also observed (not shown). For each antibody, many labeled and unlabeled somata were evident. There was no nuclear labeling and most of the reaction product was distributed around the periphery of the perikaryon. Some association of reaction product with endoplasmic reticulum and Golgi apparatus was observed (Fig. 4B). Most prominently labeled were spiny dendrites which were diffusely filled with reaction product which surrounded organelles and cytoskeletal elements (Figs. 3C, $4 D, E)$. Within this diffuse dendritic staining, more intense patches of submembranous label were often evident, which were sometimes associated with symmetrical or asymmetrical synapses (Figs. $3 B, 4 B, D$ ). Very few dendrites were only partially labeled. Within dendritic spines there was diffuse cytoplasmic labeling and also intense labeling of postsynaptic densities (Figs. $3 C, 4 D, E$ ). If silver-intensified immunogold was used as a chromogen instead of DAB, labeling was similarly distributed within somata and spiny dendrites, however more plasmalemma labeling was observed and the spine head postsynaptic densities were not as highly labeled (Yung et al., 1994). Labeled axons and axon terminals were observed with both D1 and D2 immunocytochemistry. D1 immunoreactive axon terminals were exceedingly rare (Fig. 3D), whereas D2 immunoreactive terminals were quite frequent (Fig. $5 A-J$ ). Reaction product within these terminals was diffusely located, surrounding vesicles and mitochondria. Dense deposits of reaction product at the axonal membrane were often seen (Fig. $5 B, C$ ) that were not associated with synapses. Synapses formed by D2 immunoreactive terminals were not always easy to identify due to a lack of pronounced pre- or postsynaptic densities. However, many symmetrical synapses with both D2 immunoreactive and D2 negative dendritic shafts (Fig. $5 D-F$ ) and spines (Fig. $5 G-J$ ) were identified. Axospinous D2 synapses were also observed on spine necks (Fig. $5 I$ ). Only a few D2 immunoreactive terminals forming asymmetrical synapses were observed (Fig. $5 J$ ) in all the blocks examined.

Labeled and unlabeled dendrites and spines were counted 

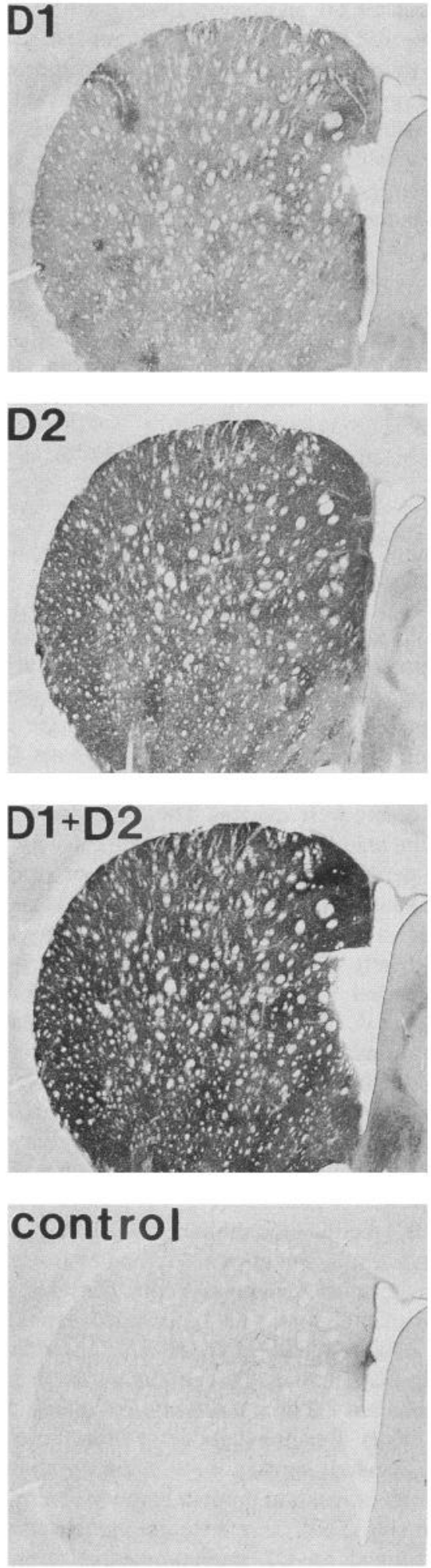
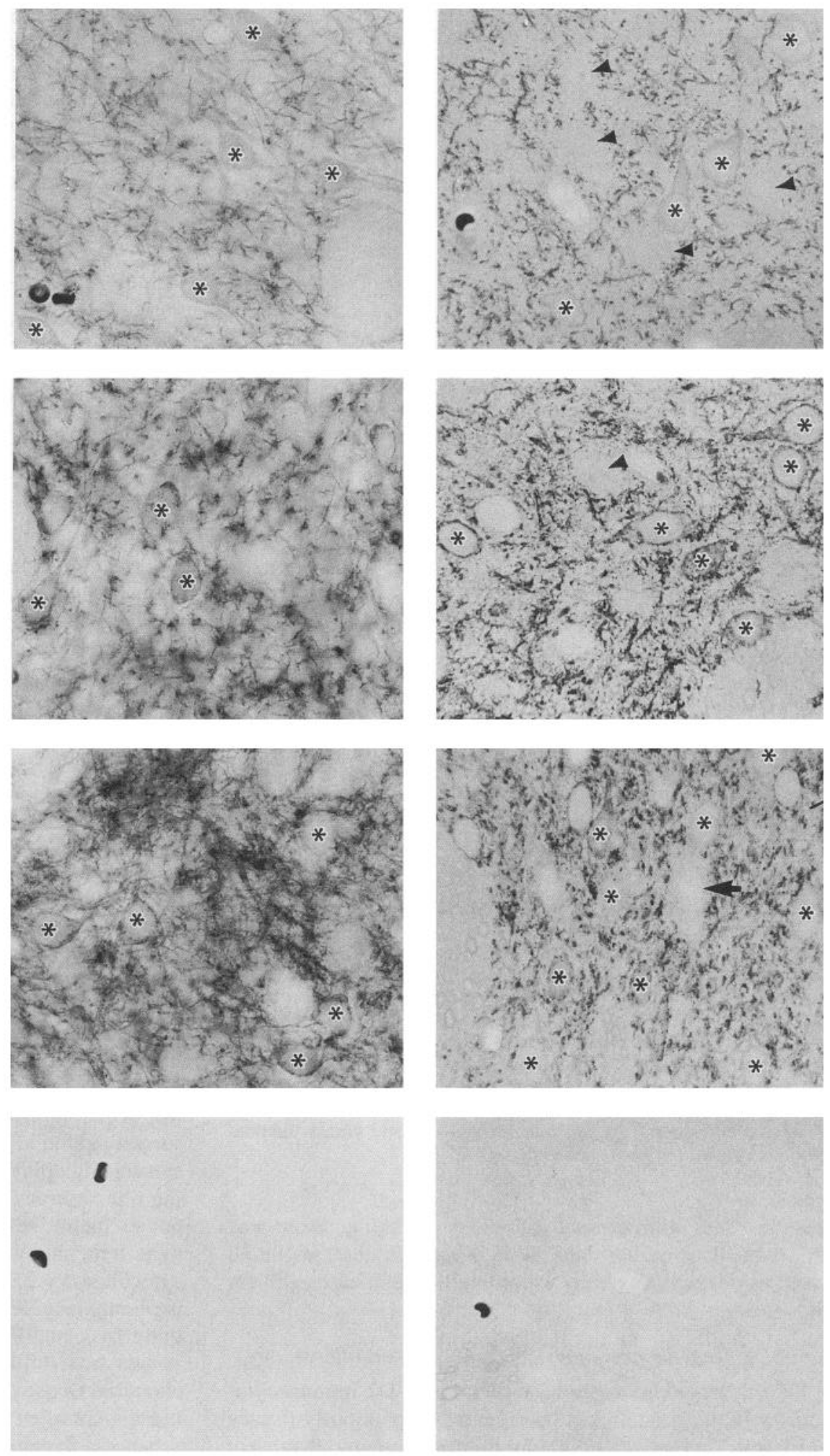

Figure 2. Light micrographs of rat striatum following immunocytochemistry for dopamine receptors. The first and second columns are low and high magnification images from $50 \mu \mathrm{m}$ thick sections. The third column contains high magnification views representative of the $2 \mu \mathrm{m}$ thick plastic sections counterstained with toluidine blue used for cell counting. Each column contains sections stained for D1, D2, D1 mixed with D2, and controls without primary antibody. Individually, both D1 and D2 immunostaining in the striatum is intense and heterogeneous with labeling of many neuronal somata and processes. At low magnification, the heterogeneity of D1 and D2 are only partially complementary. As demonstrated quantitatively, mixing D1 and D2 antibodies leads to both denser neuropil staining and the labeling of many more neurons (asterisks) than either antibody alone. Unstained neurons are marked by arrows. 

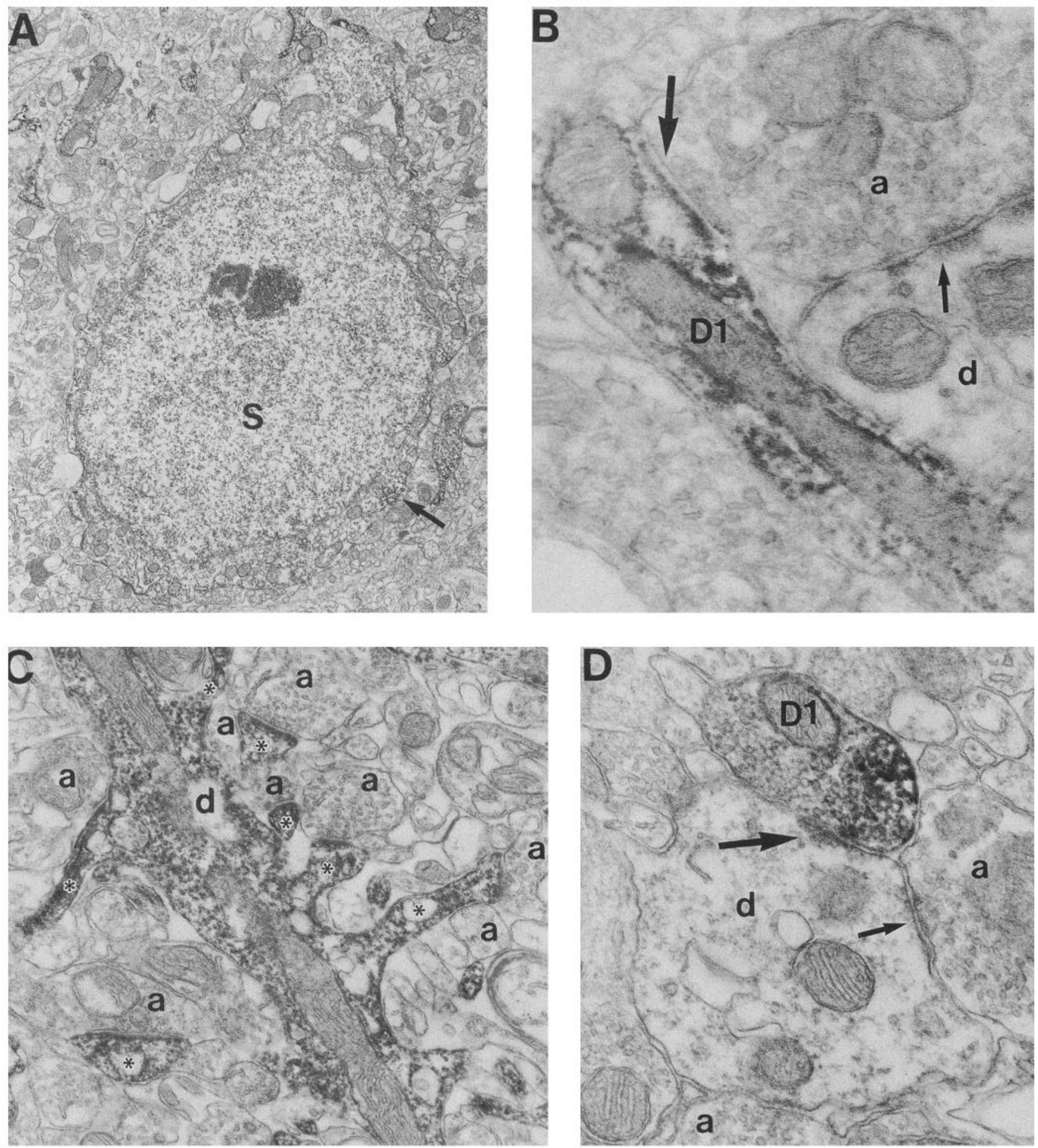

Figure 3. Electron micrographs demonstrating the subcellular localization of D1 dopamine receptor protein. A, Section through a D1 immunoreactive soma with the size and cytological features of medium spiny neurons. One patch of Golgi apparatus (arrow) has particularly dense labeling. $B$, A section through a D1 immunoreactive dendrite $(D 1)$ with reaction product coating its mitochondria and other organelles. There is a dense accumulation of reaction product at the postsynaptic density (large arrow) of a synapse received from an unlabeled axon terminal (a). This can be compared to the postsynaptic density (small arrow) of the synapse made by the same terminal with an unlabeled dendrite $(d) . C, D 1$ immunoreactive dendrite $(d)$ with many dendritic spines (asterisks) either nearby or directly arising from it. Many of these spines are receiving synapses onto their heads or necks from unlabeled axon terminals $(a)$. The postsynaptic densities are strongly labeled. $D$, An example of a rare D1-immunoreactive axon terminal $(D I)$ synapsing with an unlabeled dendrite $(d)$ that receives another synapse (small arrow) from an unlabeled axon terminal $(a)$. 

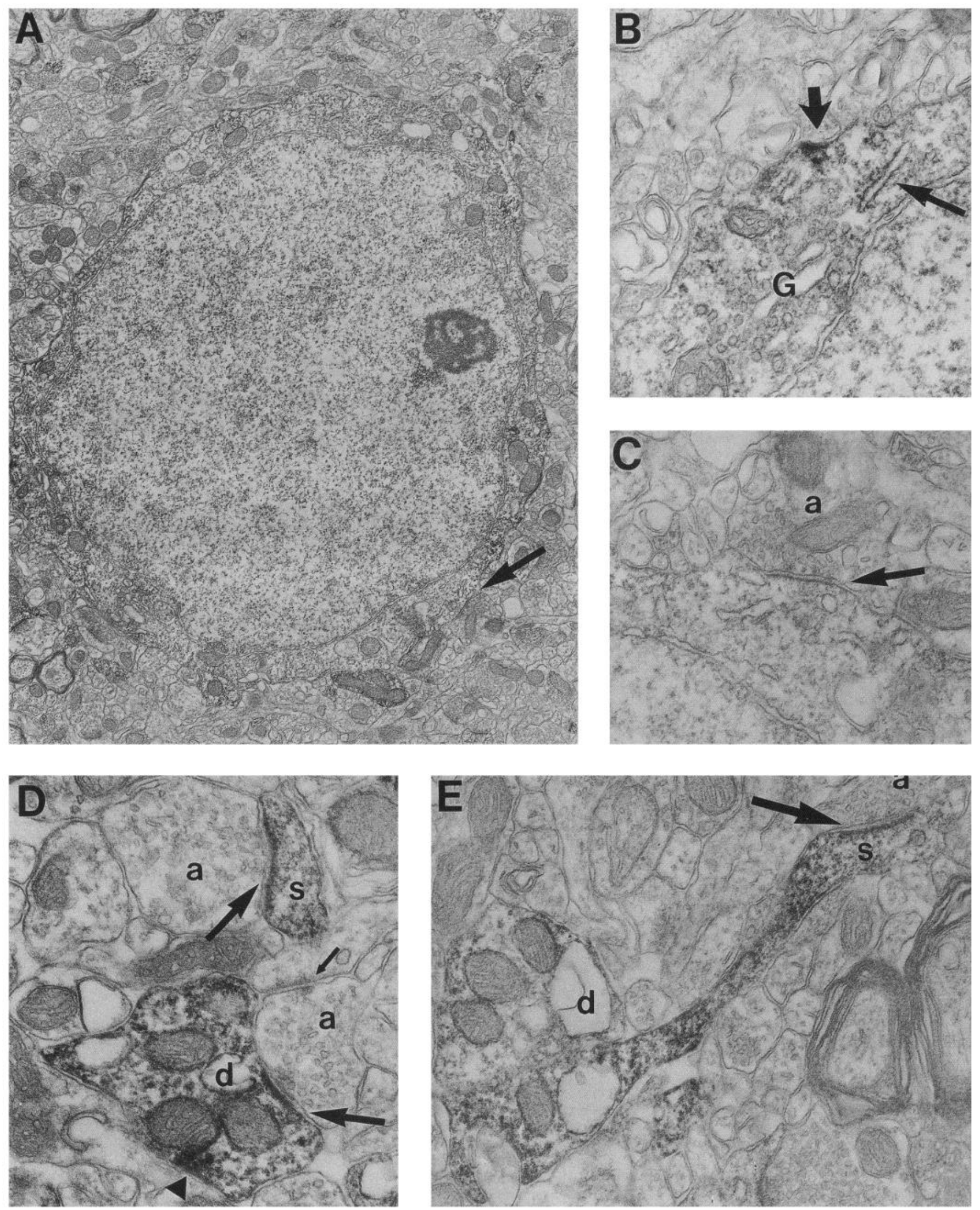

Figure 4. Electron micrographs demonstrating the subcellular localization of D2 dopamine receptor protein. A, Section through a D2 immunoreactive neuron with the size and cytology typical of a medium spiny neuron. The synapse it receives (arrow) is shown at higher magnification in $C$. $B$, A detail from the neuron in $A$ showing DAB reaction product associated with endoplasmic reticulum (long arrow), Golgi apparatus $(G)$ and with the plasma membrane (short arrow). $C$, An axosomatic synapse (arrow) between the neuron in A and an unlabeled axon terminal (a). There 

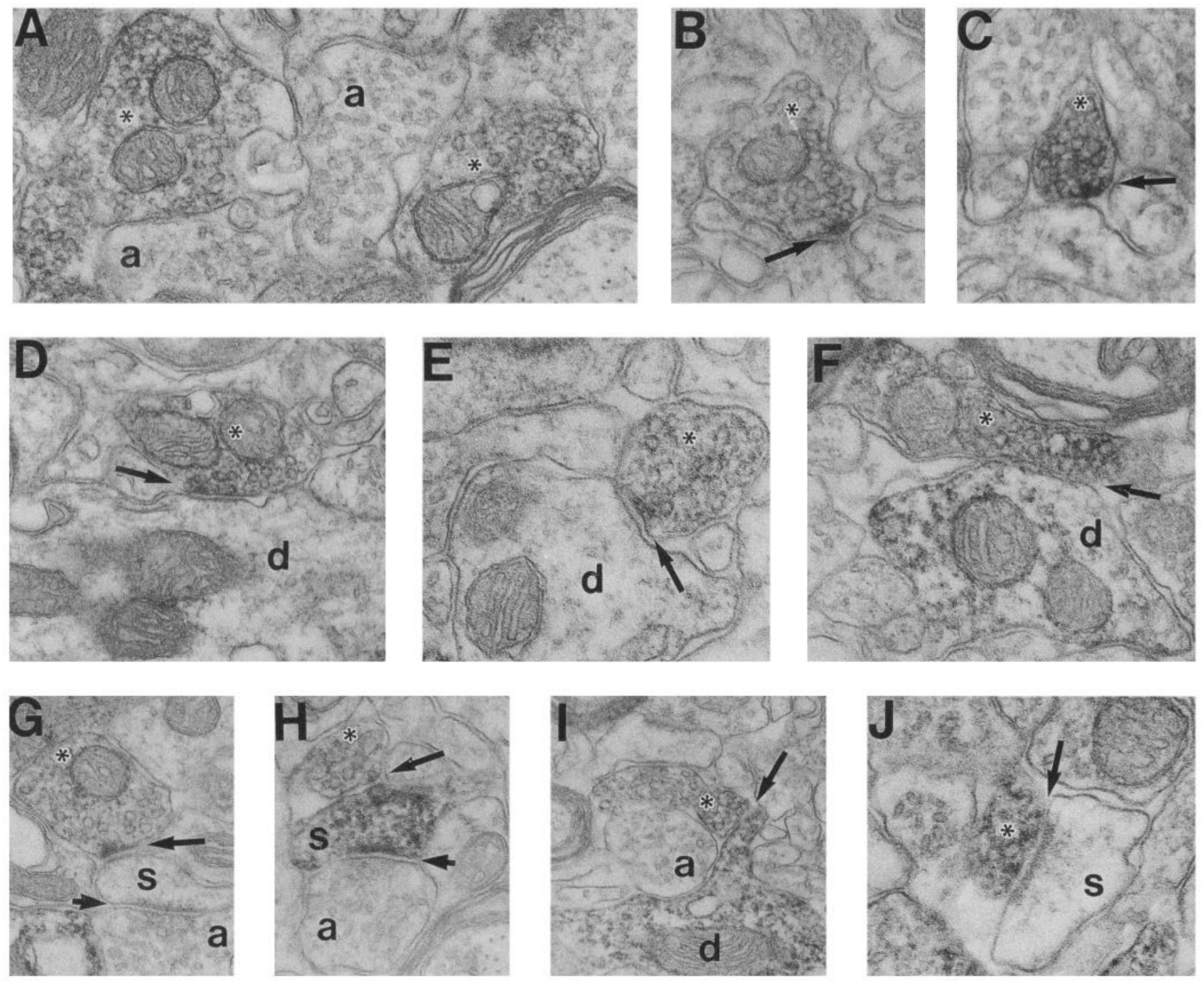

Figure 5. Electron micrographs demonstrating D2 immunoreactive axon terminals. A, Section through immunoreactive (asterisks) and unlabeled (a) axon terminals illustrating synaptic vesicle membrane labeling by DAB reaction product. $B$ and $C$, D2 immunoreactive terminals (asterisks) with labeled densities (arrows) apposed to extracellular space, rather than to synaptic membranes. $D$ and $E$, D2 immunoreactive axon terminals (asterisks) forming symmetrical synapses (arrows) with unlabeled dendrites $(d)$. F, D2 immunoreactive axon terminal (asterisk) apposed to a D2positive dendrite $(d)$. G, D2-immunoreactive axon terminal (asterisk) forming a symmetrical synapse (long arrow) with an unlabeled spine head $(s)$ which is also the recipient of an unlabeled asymmetrical synapse (short arrow) with unlabeled axon terminal (a). H, D2 axon terminal (asterisk) apposed to and possibly synapsing with (long arrow) a D2 immunoreactive spine head $(s)$ that is also the recipient of an asymmetrical synapse (short arrow) with an unlabeled axon terminal (a). I, D2 axon terminal (asterisk) apposed to and possibly synapsing with (arrow) a D2 immunoreactive spine neck arising from a labeled dendrite $(d)$. An unlabeled axon terminal $(a)$ is also in the field. $J$, Rare example of a D2 immunoreactive axon terminal $(a)$ forming an asymmetrical synapse (arrow) with an unlabeled spine $(s)$.

from montages originating from two blocks from each of three to five animals. D1 immunocytochemistry labeled $43.1 \%$ of dendritic profiles $(n=2695, \mathrm{SD}=3.7 \%)$ and $37.5 \%$ of spines $(n$ $=1442, \mathrm{SD}=7.9 \%)$ in the neuropil while D2 immunocytochemistry labeled $38.0 \%$ of dendritic profiles $(n=2592$. SD $=$ $5.7 \%)$ and $47.9 \%$ of spines $(n=1503, \mathrm{SD}=3.1 \%)$. Counts were also made of dendrites and spines in sections with combined D1 and D2 immunocytochemistry (six montages origi- nating from three animals). Combined D1 and D2 immunocytochemistry labeled $88.5 \%$ of dendritic profiles $(n=890$, SD $=2.5 \%)$ and $92.6 \%(n=571, \mathrm{SD}=2.0 \%)$ of dendritic spines.

\section{D1 and D2 receptor colocalization--electron microscopy}

In sections colabeled for D1 and D2, BDHC and DAB reaction products could be distinguished by their differences in appearance (Fig. 6). D1 (BDHC) reaction product was crystallized and

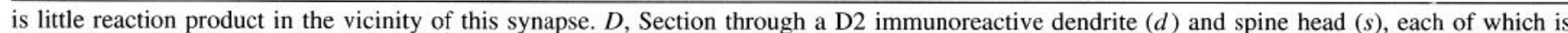

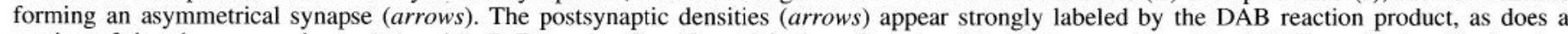

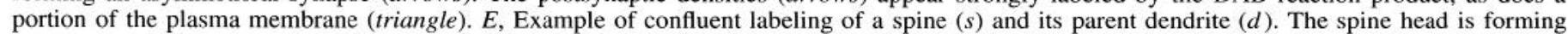
an asymmetrical synapse (arrow) with an unlabeled axon terminal $(a)$. 


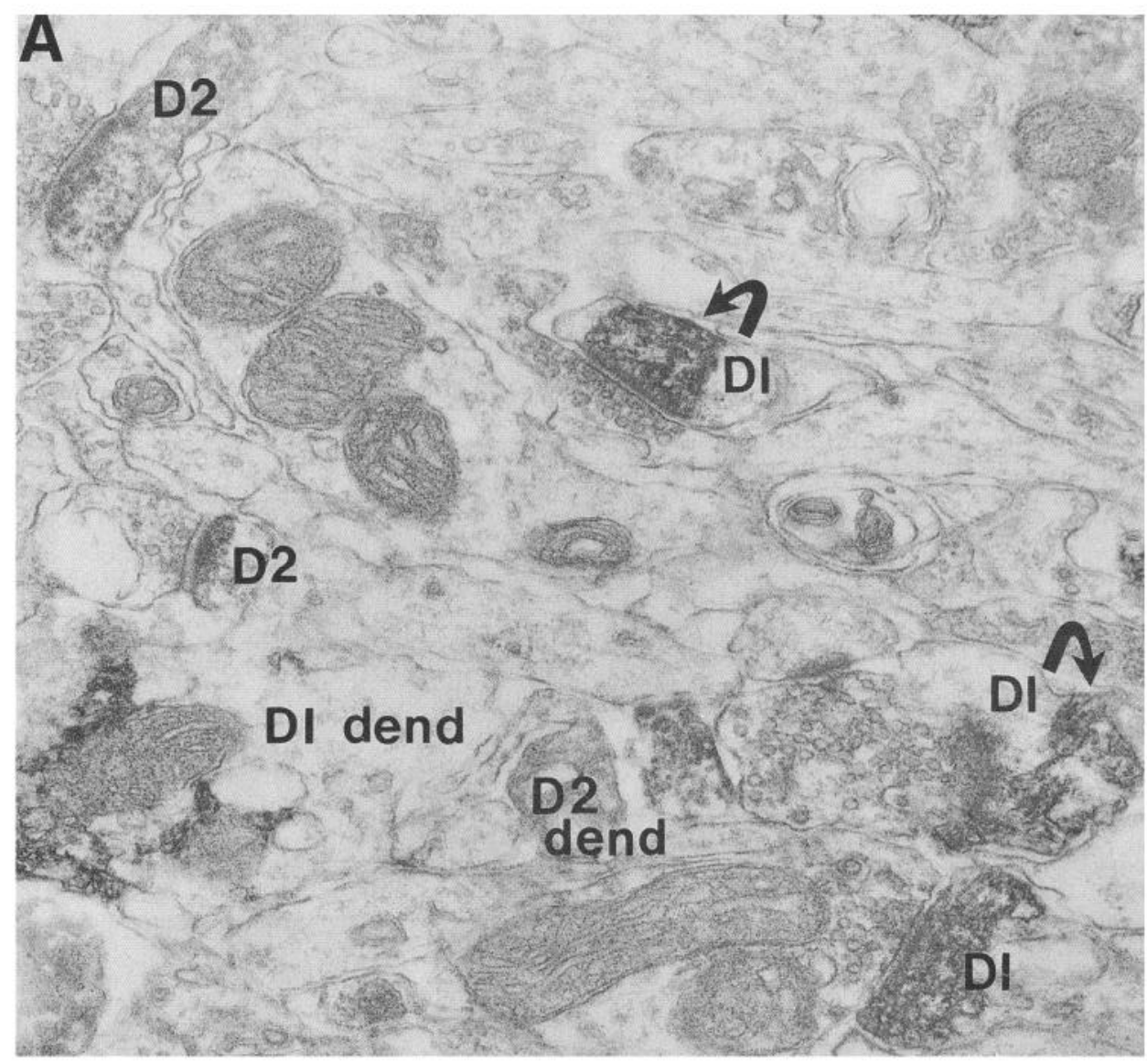

Figure 6. Electron micrographs illustrating the occurrence of D1 and D2 immunoreactivity in distinct neuropil elements. BDHC was the chromogen for D1-immunoreactive elements while DAB was the chromogen for D2. A, Electron micrograph showing multiple D1 and D2 immunoreactive spines (DI or $D 2)$ and dendrites (DI or D2 dend). $\mathrm{BDHC}$ and $\mathrm{DAB}$ are distinguishable and do not coexist within the labeled elements. $B$, Neighboring dendrites immunoreactive for D1 and D2. The condensed, punctate $\mathrm{BDHC}$ reaction product (small arrows) is in contrast to the diffuse DAB labeling (large arrow). No colocalization is evident. $C$, Neighboring D1 and D2 immunoreactive spine heads (D1 and D2) without evident colocalization. A D1 immunoreactive dendrite is also visible, containing several puncta of BDHC reaction product (arrows).
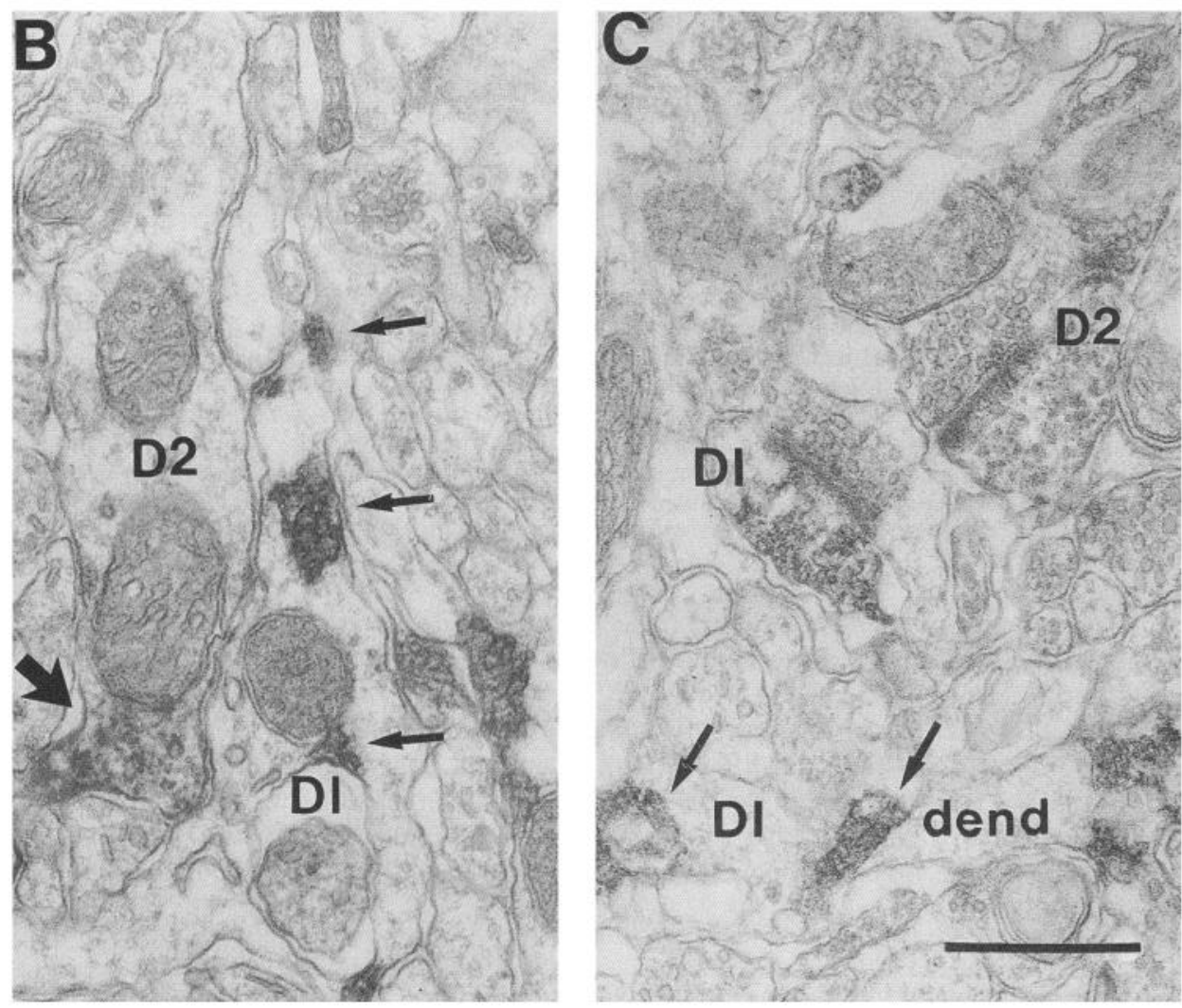
more discrete and usually did not fill the labeled process (Fig. $6 A-C$ ). D2 (DAB), was more isomorphous and diffuse, although, as described above, more discrete patches of DAB were also observed. By electron microscopy, D1 and D2 reaction products were found in distinct neuronal elements, in particular in different dendritic and spinous profiles (Fig. $6 A-C$ ). Colocalization of D1 and D2 immunoreactivity within the same structure was very rare and only a few examples were observed.

\section{Lesion sites and degeneration}

Aspiration lesions were confined within and did not extend beyond motor cortex (Fig. 7). At rostral levels, the lesions were within Frl and FL while HL and FL were more involved caudally. The lesions were at least as deep as the layer V/VI border and rarely involved the underlying white matter. With electron microscopy, degenerating corticostriatal axon terminals were frequent and easily recognized in the motor areas of the striatum (Fig. $7 H-J)$. Most were at a similar stage of degeneration, being highly electron dense and containing few recognizable organelles other than swollen mitochondria and some vesicular elements. Their synapses (Fig. $7 H-J$ ), which were primarily with spines, were identified by the presence of a widened synaptic cleft and a postsynaptic density. All identified corticostriatal synapses were asymmetrical and many were with D1 (Fig. $7 I$ ) or D2 (Fig. $7 J$ ) immunoreactive spines.

\section{Injection sites and BD-labeled axons}

BD injection sites were confined within motor cortex and spanned its entire thickness while being densest in layers III-IV (Fig. 7B). The injection sites contained many labeled fibers and neurons with somata occurring in each layer. Ipsilateral to the injections there were retrogradely labeled pyramidal cells (primarily supragranular) in the neighboring parietal cortex. Labeled axons descended to the subcortical white matter and spread both medially and laterally along the corpus callosum. Along the dorsal and lateral edge of the striatum, fibers turned directly into the striatal parenchyma or entered Wilson's pencils which were especially well labeled in the dorsolateral quadrant. At higher magnification, corticostriatal axons and terminal fields were very evident in the motor striatum (Fig. 7C). Labeled axons could easily be followed across the corpus callosum to the contralateral hemisphere (Fig. 7A). In animals that received both a lesion and an injection of $\mathrm{BD}$, a few lightly stained pyramidal cells were retrogradely labeled in motor cortex peripheral to the aspiration lesion. Though much lighter than on the ipsilateral side, contralateral axons were also evident along the corpus callosum, in Wilson's pencils, and in terminal fields in the motor striatum.

BD labeling in the striatum was examined by electron microscopy in sections with and without D1 or D2 receptor immunocytochemistry and was very evident within myelinated axons, unmyelinated axons, and axon terminals (Fig. $7 D$ ). In preterminal axons, DAB was primarily evident coating microtubules. In axon terminals, DAB coated but did not obscure the mitochondria and synaptic vesicles. In agreement with earlier studies (Kemp, 1968; Kemp and Powell, 1971; Hassler et al., 1978; IIattori et al., 1979; Frotscher et al., 1981; Somogyi et al., 1981; Bolam, 1984), synapses formed by BD-labeled axon terminals were asymmetrical and primarily with spine heads (Fig. $7 D-G$ ) but also with dendrites (Fig. $7 E$ ). Many of the synapses were with D1 (Fig. $7 F$ ) or D2 (Fig. $7 G$ ) immunoreactive spines. Since BD-labeled axon terminals were more densely stained and formed only asymmetrical synapses, they were easily distin- guishable from D1 or D2-labeled axon terminals which were lighter and almost exclusively formed symmetrical synapses.

\section{Corticostriatal synapses with DI and D2 immunoreactive processes}

Synapses between degenerating (ipsilateral) or BD labeled (contralateral) axon terminals and unlabeled or dopamine receptor immunoreactive dendrites and spines were counted from electron micrograph montages. These montages originated from two blocks from each of four animals (eight montages for each antibody). In the D1 montages, degenerating axon terminals accounted for $8.0 \%(n=98, \mathrm{SD}=4.3 \%)$ of all axon terminals while BD-labeled axon terminals accounted for $3.6 \%(n=61$, $\mathrm{SD}=2.2 \%$ ). In the $\mathrm{D} 2$ montages, degenerating axon terminals accounted for $10.1 \%(n=128, \mathrm{SD}=5.3 \%)$ of all axon terminals while BD-labeled axons terminals accounted for $4.8 \%$ ( $n$ $=86, \mathrm{SD}=3.5 \%$ ). Ipsilateral degenerating corticostriatal terminals synapsed significantly more frequently with D1 immunoreactive spines than with D2 immunoreactive spines $(65.3 \%$ vs $47.1 \%$ of identified terminals; $t=4.22, p=0.002$, twotailed). This difference was not found for contralateral BD labeled corticostriatal axospinous synapses (45.5\% for D1 and $52.5 \%$ for D2; $t=-0.82, p=0.427$, two-tailed). A striking difference between ipsilateral and contralateral corticostriatal synapses was that a much higher proportion of contralateral corticostriatal synapses were with dendritic shafts $(30 \%)$ than ipsilateral corticostriatal synapses $(4 \%)$. There was no difference in the proportions of contralateral axon terminals synapsing with D1 or D2 dendrites. Figure 8 is a diagrammatic summary of these findings.

It is conceivable that cortical lesions could lead to regulatory changes affecting the immunoreactivity of postsynaptic elements. To test this possibility, synapse counts were made of ipsilateral BD-labeled corticostriatal terminals synapsing with D1 or D2 spines in two animals that did not have lesions. In these animals, the proportions of synapses that were with D1 and D2 spines were similar to the proportions determined using lesion-induced degeneration to label corticostriatal terminals. Using BD as an ipsilateral anterograde marker, $62.0 \%$ of 268 identified synapses were with DI immunoreactive spines while $47.2 \%$ of 180 were with D2 immunoreactive spines.

\section{Discussion}

The results of the present study include several major findings related to the cellular and subcellular distribution of D1 and D2 dopamine receptor proteins and to the synaptic relations of motor corticostriatal afferents with dendrites expressing them. First, both receptor proteins are expressed at high levels in the dorsal striatum in a heterogeneous and partially complementary manner. Second, both receptors are expressed by subsets of medium sized neurons. Third, colocalization experiments and quantitative data indicates that these subsets represent largely distinct populations, although relatively limited overlap cannot be excluded. Fourth, there is much more presynaptic D2 than D1 labeling and neither are found within axon terminals forming asymmetrical synapses. Fifth, ipsilatcral motor corticostriatal afferents synapse significantly more frequently with D1 than D2 immunoreactive dendrites. Sixth, almost all ipsilateral corticostriatal afferents synapse with spines while many contralateral corticostriatal afferents synapse directly onto dendritic shafts. The validity of most of these findings depends upon the specificity and sensitivity of the dopamine receptor antibodies. The 

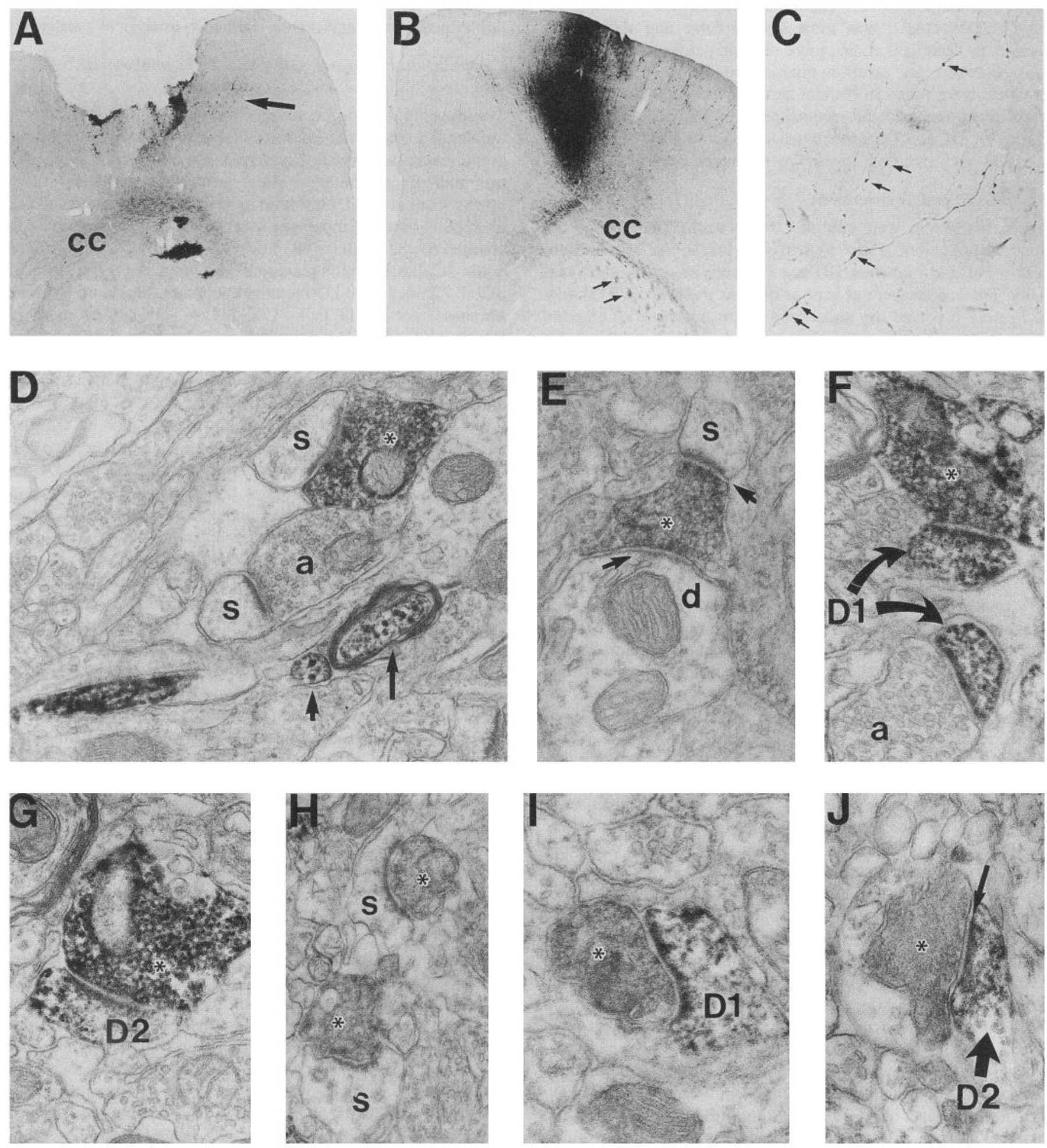

Figure 7. Light and electron micrographs demonstrating the sites of aspiration lesions and of BD injections, and labeled corticostriatal axons, terminals, and synapses. A, The damage from an aspiration lesion of motor cortex is visible as a defect in the cortex with underlying hemorrhage and damage extending to the subcortical white matter. The hemorrhagic fragments overlying the striatum were broken off from the cortex during section handling and do not indicate striatal damage. Labeled neurons and axons from the contralateral BD injection are also visible with retrogradely neurons especially visible lateral to the lesion (arrow) and many labeled axons present in the corpus callosum ( $c c$ ). B, BD injection into motor cortex with some retrogradely labeled neurons visible peripheral to the injection site and labeled axons apparent in the corpus callosum and in Wilson's pencils (arrows). $C$, Light micrograph of BD labeled axons in the striatum with many terminals evident (arrows). D, Electron micrograph demonstrating myelinated (large arrow) and unmyelinated (small arrow) BD-labeled corticostriatal axons and an axon terminal (asterisk) synapsing with an unlabeled spine $(s)$. An unlabeled axon terminal $(a)$ synapsing with a spine $(s)$ is also visible. $E$, BD-labeled corticostriatal axon terminal (asterisk) synapsing with a spine $(s)$ and a dendrite $(d) . F, \mathrm{D} 1$ immunoreactive dendritic spines (arrows) synapsing with a BD-labeled corticostriatal axon terminal (asterisk) and with an unlabeled axon terminal $(a)$. G, BD-labeled corticostriatal axon terminal (asterisk) synapsing with a D2 

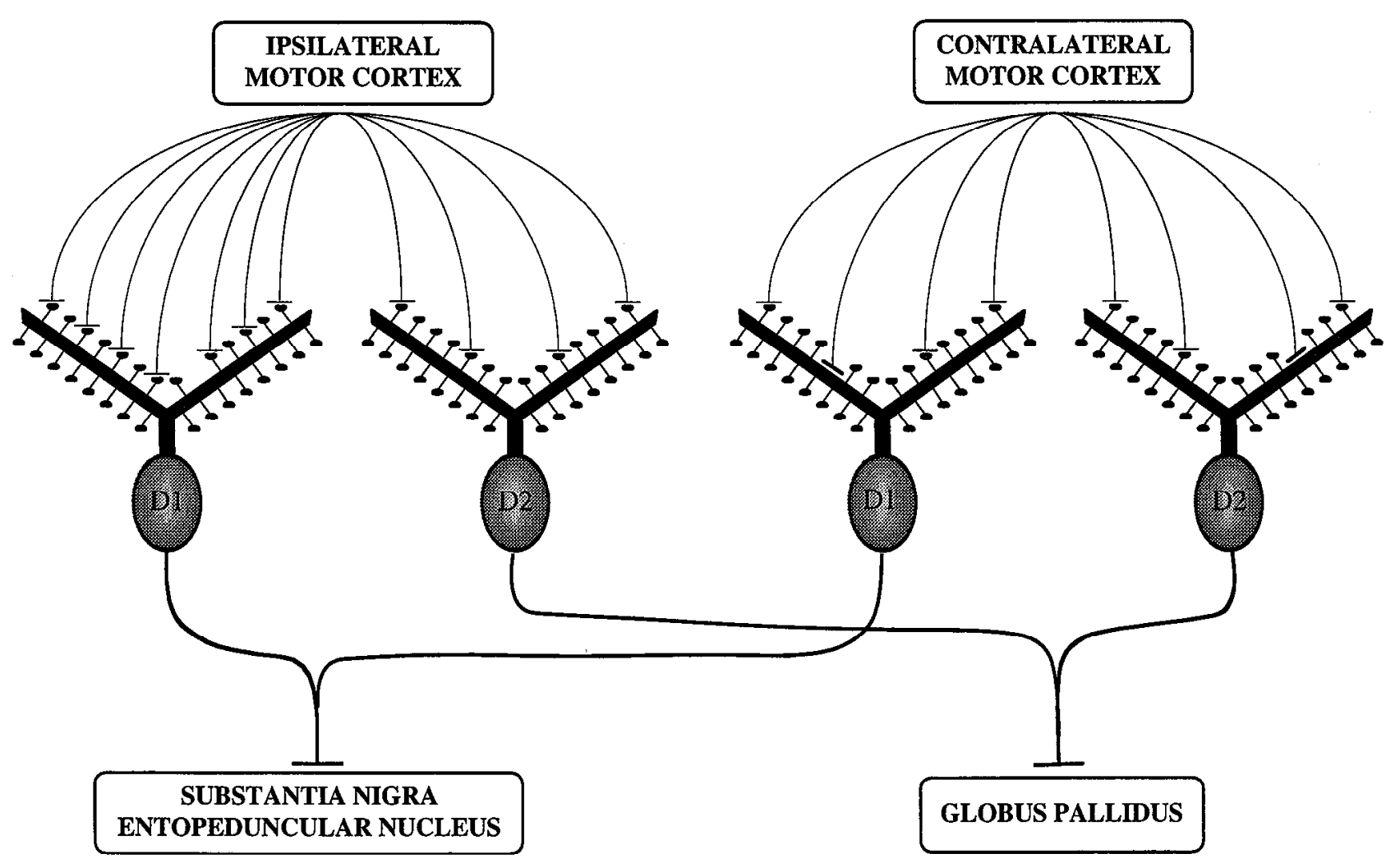

Figure 8. Summary diagram illustrating the ipsilateral and contralateral motor corticostriatal connectivity of D1 and D2 immunoreactive neurons and their predominant extrastriatal projections.

specificity and lack of cross-reactivity of the polyclonal antibodies has been established by Western blotting, immunoprecipitation, and immunocytochemistry (Levey et al., 1993). The D1 monoclonal antibody has not been previously reported but was shown here to be monospecific for native and cloned D1 receptor. By light and electron microscopy, the distributions of D1 protein, as determined by the polyclonal and monoclonal antibodies, were indistinguishable.

\section{Cellular expression of dopamine receptors-quantification}

In the present study, the proportions of neuronal perikarya expressing D1 or D2 immunoreactivity (53\% and $47 \%$, respectively) at the light microscopic level, were remarkably similar to the proportions determined utilizing in situ hybridization (Weiner et al., 1991; Le Moine et al., 1991; Gerfen, 1993). These results confirm, at the protein level, that significant quantities of the receptors are expressed in distinct populations of striatal neurons. Although the lower limits of perikaryal dopamine receptor protein detection by immunocytochemistry are unknown, they are at least comparable to mRNA detection by in situ hybridization.

This study addresses the possibility of neurons and neuronal processes coexpressing D1 and D2 at the level of sensitivity permitted by immunocytochemistry. Our hypothesis was that coexpression of both receptors in significant numbers of neurons would lead to fewer labeled neurons when D1 and D2 immunocytochemistry is combined than the sum of the neurons labeled separately. This strategy is unlikely to affect the individual sensitivity of the antibodies, and it permits a quantitative estimation of their possible overlap in neurons (by light microscopy) and neuronal processes (by electron microscopy). The $78 \%$ of striatal perikarya labeled by combined D1 and D2 immunocytochemistry, as compared to a sum of $101 \%$ with individual labeling, suggests that some proportion of neurons could express both receptors but that most express D1 or D2 exclusively. However, the variation associated with these numbers is sufficiently large to make precise estimates of the extent of possible overlap with this technique uncertain. The potential for coexpression seems much lower at the level of dendrites and spines where combined immunocytochemistry labels as many as are labeled individually for D1 and D2. Thus, this approach provides quantitative evidence for modest coexpression of D1 and D2 in neuronal perikarya but minimal coexpression in dendrites and spines. This discrepancy could be explained by technical limitations. Since neuronal processes are better stained than somata, the dendrite and spine counts are likely to be more precise. Alternatively, there may be significant colocalization within perikarya that is not present within dendrites and spines due to precise regulation of intracellular transport of the receptors. These

$\leftarrow$

immunoreactive spine (D2). H, Examples of corticostriatal axon terminals (asterisks) labeled by lesion induced degeneration and synapsing with unlabeled dendritic spines $(s)$. Synaptic vesicles and deformed mitochondria are visible through the condensed degenerating spine cytoplasm. $I$, Synapse between a degenerating corticostriatal axon terminal (asterisk) and a D1 immunoreactive spine (DI). $J$, Synapse between a degenerating corticostriatal axon terminal (asterisk) and a D2 immunoreactive spine (arrow). 
latter two sites are presumably the locations where dopamine receptors are most available to dopamine.

To more directly examine the possibility of coexpression of D1 and D2 receptor proteins, we colabeled them using D $\triangle B$ and $\mathrm{BDHC}$ as distinct chromogens for D1 and D2. Labeling in these experiments was not quantified since the $\mathrm{BDHC}$ reaction product is discontinuous and may be less sensitive than DAB for identifying small dendrites and spines, and since minor changes in reaction conditions greatly affect its appearance (Levey et al., 1986). Nevertheless, examining many sections with excellent double labeling, it was extremely difficult to identify any neurons or neuronal processes coexpressing D1 and D2. Thus, taken together, our quantitative and qualitative data strongly support the premise that the majority of striatal neurons predominantly express either D1 or D2 (Gerfen et al., 1990).

\section{Postsynaptic dopamine receptors}

Similar to other techniques, immunocytochemistry indicates that D1 and D2 dopamine receptor subtypes are abundantly expressed in striatal neurons. Immunoelectron microscopy confirms that the majority of these neurons have the morphological features previously described for medium spiny neurons (Somogyi and Smith, 1979; Wilson and Groves, 1980). In addition, D2 was occasionally localized in neurons with richer cytoplasm and an enfolded nucleus, suggestive of striatal interneurons. Immunoreactivity for both dopamine receptor subtypes is especially intense in spiny dendrites. Concentrated localization at probable nigrostriatal synapses has not been discernible since labeling is so homogeneous in a given dendrite or spine and the observed dense deposits of submembranous label are most commonly extrasynaptic. Furthermore, labeled spiny dendrites were not observed to give rise to unlabeled dendritic spines, suggesting that the majority of spines contain dopamine receptors, while only a limited number of them can be expected to directly receive dopaminergic synapses (Freund et al., 1984). This widespread localization could be due to diffusion of the DAB reaction product or immunogold, to labeling of receptors during their intracytoplasmic journeys to and from functional sites, to the presence of spare receptors, or to widespread synaptic and extrasynaptic membrane localization of functional receptor proteins that could respond to both synaptic and extrasynaptic dopamine (volume transmission).

\section{Presynaptic dopamine receptors}

The current findings do not suggest a major role for presynaptic D1 receptors in the striatum since D1-immunoreactive axon terminals were extremely rare, seemingly too rare to even account substantially for diffusion of receptor into the local axon collaterals of D1 neurons. In contrast, presynaptic D2 receptors were readily identified in many axon terminals in the striatum. They have previously been postulated to occur on corticostriatal axon terminals, where release of glutamate appears to be inhibited by dopamine receptors (Schwarcz et al., 1978; Rowlands and Roberts, 1980) with D2 pharmacologic properties (Theodorou et al., 1981; Filloux et al., 1988; Yamamoto and Davy, 1992). However, there has been disagreement about whether these receptors are located presynaptically on corticostriatal axon terminals or whether they are postsynaptic and act through polysynaptic pathways to affect the cortex (Palacios, 1986; Joyce and Marshall, 1987; Malenka and Kocsis, 1988; Peris et al., 1988; Garcia et al., 1991; Yamamoto and Davy, 1992). Although we observe low levels of D2 immunoreactivity in cortical pyramidal cells
(Levey et al., 1993) and D2 mRNA is present in cortex, albeit at much lower levels than in striatum (Monsma et al., 1989; Meador-Woodruff and Mansour, 1991; Weiner et al., 1991), almost no D2 immunoreactive axon terminals forming asymmetrical synapses were observed. Since corticostriatal terminals are well established to be exclusively asymmetrical, the current study found no evidence suggesting $\mathrm{D} 2$ receptors are localized in corticostriatal terminals. This negative finding could be due to receptor abundance in corticostriatal axon terminals that is beneath the threshold of detection by immunocytochemistry. However, other types of D2 receptor containing axon terminals were easily recognized. An alternative explanation is that presynaptic corticostriatal dopamine receptors are not recognized by our antibodies due to molecular differences not resolved by current receptor agonists. Specifically, other D2 subfamily members, such as D3 or D4, which are pharmacologically similar to D2 (Sibley, 1992), could be presynaptic corticostriatal receptors.

Presynaptic D2-like receptors on nigrostriatal terminals (autoreceptors) inhibit dopamine release (Nieoullon et al., 1978; Cheramy et al., 1986; Romo et al., 1986; Krebs et al., 1991). We have previously demonstrated that $\mathrm{D} 2$ receptor protein is expressed by neurons in the substantia nigra, pars compacta (Levey et al., 1993). D2-immunoreactive axon terminals identified in the current study form symmetrical synapses with dendritic shafts and spines which is consistent with the morphology of nigrostriatal terminals as identified by tyrosine hydroxylase immunocytochemistry (Freund et al., 1984). Indeed, double-labeling studies have colocalized tyrosine hydroxylase with D2 in some striatal axons (Sesack et al., 1994). It is not yet known whether some D2-containing axon terminals arise from local axon collaterals of D2 neurons.

\section{Corticostriatal relations}

In rat and monkey, the striatum receives topographic projections from the entire cerebral cortex (Webster, 1961; Goldman-Rakic and Selemon, 1986; McGeorge and Faull, 1989). In the rat, motor areas of cortex project longitudinally along the dorsolateral striatum and distinct cortical regions project differentially to patch and matrix areas of striatum (Donoghue and Herkenham, 1986; Ebrahimi et al., 1992). Superficial cortical pyramidal cells project to matrix areas while deeper pyramidal cells project to patch areas (Gerfen, 1989). In the monkey, it has been shown that primary motor cortex projects preferentially to discrete areas within the matrix ("matrisomes") (Flaherty and Graybiel, 1993) while ipsilateral and contralateral motor cortex projections have been found to interdigitate, rather than overlap (Flaherty and Graybiel, 1993). In the current study, ipsilateral and contralateral corticostriatal axon terminals were differentially labeled by lesion-induced degeneration or BD. By electron microscopy, regions rich in ipsilateral but poor in contralateral corticostriatal terminals were observed as were the converse. This may be consistent with some degree of spatial separation, however the methods used are not precise enough to be conclusive.

Many motor cortex axon terminals were found to synapse with spines and dendrites expressing D1 or D2 receptor proteins. This finding demonstrates that the motor cortex makes direct synaptic connections with striatal neurons expressing both dopamine receptor subtypes. A significantly higher percentage of ipsilateral motor corticostriatal synapses were with D1 immunoreactive spines than were with D2 immunoreactive spines (65\% vs $47 \%$ ). Since D2 immunocytochemistry labeled more spines in the neuropil than D1 immunocytochemistry, this dif- 
ference could not be due to underlabeling of D2. This difference indicates that D1 and D2 immunocytochemistry does not label identical populations of spines and or neurons. The neuron, dendrite, and spine counts as well as the colocalization experiments further suggest that it is unlikely that D1 and D2 spines could arise from the same neurons or that many spines might coexpress both receptor subtypes. To the extent that D1 and D2 receptors distinguish striatal neurons projecting to the substantia nigra pars reticulata and entopeduncular nucleus from those projecting to the globus pallidus (Gerfen et al., 1990), these results indicate that motor cortex is more highly connected to striatonigral neurons than to striatopallidal neurons. It is not yet known whether other cortical regions, such as associative and limbic areas, project differentially to D1 and D2 neurons.

Quantification of corticostriatal synapses at the electron microscopic level is complicated by the difficulty of labeling all the axons in a projection, by variability in the method of visualization, and by the fact that synapses cannot be reliably identified in all planes of section. These considerations mean that counts of identified synapses necessarily underestimate the entire projection. Thus our absolute and percentage data can be considered minimums. Since there is no reason to suspect that identified synapses would systematically differ from unidentified synapses, valid comparisons between conditions can be made. An additional consideration in the current study is the possibility that using lesion-induced degeneration to mark corticostriatal synapses might affect postsynaptic cxpression of dopamine receptors. With the $4 \mathrm{~d}$ survival intervals used, dopamine receptor immunocytochemistry is not affected at the light microscopic level by cortical lesions. Furthermore, similar percentages of dendrites and spines are labeled in the neuropil in lesioned and unlesioned animals. Finally, the percentages of ipsilateral corticostriatal synapses that were with D1 or D2 spines were similar when they were marked either by cortical lesions or by BD.

It has long been known that a significant proportion of corticostriatal afferents are contralateral in origin (Jones et al., 1977; Royce, 1982; Fisher et al., 1984; Arikuni and Kubota, 1986; McGeorge and Faull, 1987; Wilson, 1987). Few differences between ipsilateral and contralateral projections have been identified, although the contralateral projection is less extensive and recent studies have suggested that cholecystokinin is present in contralateral but not ipsilateral projecting axons (Morino et al., 1992; You et al., 1994). Unlike the ipsilateral projections, contralateral corticostriatal afferents synapse with similar numbers of dendrites expressing D1 and D2. This indicates that contralateral motor cortex afferents may equally influence both the striatopallidal and striatonigral output pathways. An interesting finding that has not been previously reported is that while only a few percent of ipsilateral corticostriatal synapses were axodendritic, as many as a third of contralateral corticostriatal synapses were. Whether axodendritic corticostriatal synapses are closer to the somata than axospinous synapses was not determined and, given the small caliber of many of the postsynaptic dendrites, cannot be assumed. This finding may reflect basic differences in how ipsilateral and contralateral afferents effect individual striatal neurons. There is little direct knowledge about how the response properties of axodendritic and axospinous synapses may differ. However, the plasticity of spine morphology according to their history of excitation and their involvement in mnestic processes such as long term potentiation, has suggested that axospinous synapses respond dynamically to ongoing synaptic conditions (Harris and Kater, 1994). Such plasticity has not been readily demonstrated for axodendritic synapses which may serve a more modulatory or gating function.

\section{References}

Ariano MA, Stromski CJ, Smyk REM, Sibley DR (1992) D2 dopamine receptor localization on striatonigral neurons. Neurosci Lett 144:215-220.

Ariano MA, Fisher RS, Smyk RE, Sibley DR, Levine MS (1993) D2 dopamine receptor distribution in the rodent CNS using anti-peptide antisera. Brain Res 609:71-80.

Arikuni T, Kubota K (1986) The organization of prefrontocaudate projections and their laminar origin in the macaque monkey: a retrograde study using HRP-gel. J Comp Neurol 244:492-510.

Bolam JP (1984) Synapses of identified neurons in the striatum. Ciba Found Symp 107:30-47.

Boundy VA, Luedtke RR, Artymyshyn RP, Filtz TM, Molinoff PB (1993) Development of polyclonal anti-D2 dopamine receptor antibodies using sequence-specific peptides. Mol Pharmacol 43:666676.

Chen JF, Qin ZH, Szele F, Bai G, Weiss B (1991) Neuronal localization and modulation of the D2 dopamine receptor mRNA in braill of normal mice and mice lesioned with 6-hydroxydopamine. Neuropharmacology 30:927-941.

Cheramy A, Romo R, Godeheu G, Baruch P, Glowinski J (1986) In vivo presynaptic control of dopamine release in the cat caudate nucleus. II. Facilitatory or inhibitory influence of L-glutamate. Neuroscience 19:1081-1090

Ciliax B, Hersch S, Levey A (1994) Immunocytochemical localization of D1 and D2 receptors in the rat brain. In: Dopamine receptors and transporters: pharmacology, structure, and function (Niznik HB, ed), pp 383-399. New York: Dekker.

Dearry A, Gingrich JA, Falardeau P, Fremeau RTJ, Bates MD, Caron MG (1990) Molecular cloning and expression of the gene for a human D1 dopamine receptor. Nature 347:72-76.

Deutscher MP, ed (1990) Methods in enzymology, Vol 182, Guide to protein purification. San Diego: Academic.

Donoghue JP, Herkenham M (1986) Neostriatal projections from individual cortical fields conform to histochemically distinct striatal compartments in the rat. Brain Res 365:397-403.

Ebrahimi A, Pochet R, Roger M (1992) Topographical organization of the projections from physiologically identified areas of the motor cortex to the striatum in the rat. Neurosci Res 14:39-60.

Filloux F, Liu T, Hsu C, Hunt M. Wamsley J (1988) Selective cortical infarction reduces $\left[{ }^{3} \mathrm{H}\right]$ sulpiride binding in rat caudate-putamen: autoradiographic evidence for presynaptic D2 receptors on corticostriate terminals. Synapse 2:521-531.

Fisher RS, Shiota C, Levine MS, Hull CD, Buchwald NA (1984) Interhemispheric organization of corticocaudate projections in the cat: a retrograde double-labelling study. Neurosci Lett 84:369-373.

Flaherty A, Graybiel A (1993) Two input systems for body representation in the primate striatal matrix: experimental evidence in the squirrel monkey. J Neurosci 13:1120-1137.

Fremeau RTJ, Duncan GE, Fornaretto MG, Dearry A, Gingrich JA, Breese GR, Caron MG (1991) Localization of Dl dopamine receptor mRNA in brain supports a role in cognitive, affective, and neuroendocrine aspects of dopaminergic neurotransmission. Proc Natl Acad Sci USA 88:3772-3776.

Freund TF, Powell JF, Smith AD (1984) Tyrosine hydroxylase-immunoreactive boutons in synaptic contact with identified striatonigral neurons, with particular reference to dendritic spines. Neuroscience 13:1189-1215.

Frotscher M, Rinne U, Hassler R, Wagner A (1981) Termination of cortical afferents on identified neurons in the caudate nucleus of the cat. Exp Brain Res 41:329-337.

Garcia MM, Young SJ, Groves PM (1991) Terminal excitability of the corticostriatal pathway. I. Regulation by dopamine receptor stimulation. Brain Res 551:195-206.

Gerfen CR (1989) The neostriatal mosaic: striatal patch-matrix organization is related to cortical lamination. Science 246:385-388.

Gerfen C (1993) Segregation of D1 and D2 dopamine receptor mRNA in separate populations of striatal neurons. Soc Neurosci Abstr 133.

Gerfen C, Engber T, Mahan L, Susel Z, Chase T, Monsma F, Sibley D (1990) D1 and D2 Dopamine receptor-regulated gene expression of striatonigral and striatopallidal neurons. Science 250:1429-1431. 
Goldman-Rakic P, Selemon L (1986) Topography of corticostriatal projections in nonhuman primates and implications for functional parcellation of the neostriatum. Cereb Cortex 447-466.

Harris K, Kater S (1994) Dendritic spines: cellular specializations imparting both stability and flexibility to synaptic function. In: Annual review of neuroscience, pp 341-371. Palo Alto, CA: Annual Reviews.

Hassler R, Chung J, Rinne U, Wagner A (1978) Selective degeneration of two out of the nine types of synapses in cat caudate nucleus after cortical lesions. Exp Brain Res 31:67-80.

Hattori T, McGeer EG, McGeer PL (1979) Fine structural analysis of the cortico-striatal pathway. J Comp Neurol 185:347-354.

Huang Q, Zhou D, Chase K, Gusella JF, Aronin N, DiFiglia M (1992) Immunohistochemical localization of the D1 dopamine receptor in rat brain reveals its axonal transport, pre- and postsynaptic localization, and prevalence in the basal ganglia, limbic system, and thalamic reticular nucleus. Proc Natl Acad Sci USA 89:1198811992.

Jarvie KR, Booth G, Brown EM, Niznik HB (1989) Glycoprotein nature of dopamine D1 receptors in the brain and parathyroid gland. Mol Pharmacol 36:566-574.

Jones E, Coulter J, Burton H, Porter R (1977) Cells of origin and terminal distribution of corticostriatal fibers arising in the sensorymotor cortex of monkeys. J Comp Neurol 173:53-80.

Joyce JN, Marshall JF (1987) Quantitative autoradiography of dopamine D2 sites in rat caudate-putamen: localization to intrinsic neurons and not to neocortical afferents. Neuroscience 20:773-795.

Kemp JM (1968) An electron microscopic study of the termination of afferent fibers in the caudate nucleus. Brain Res 11:464-467.

Kemp JM, Powell TPS (1971) The connexions of the striatum and globus pallidus: synthesis and speculations. Philos Trans R Soc Lond [Biol] 262:441-457.

Krebs M-O, Travero F, Desban M, Gauchy C, Glowinski J, Kemel M-L (1991) Distinct presynaptic regulation of dopamine release through NMD $\Lambda$ receptors in striosome- and matrix-enriched areas of the rat striatum. J Neurosci 11:1256-1262.

Le Moine C, Tison F, Bloch B (1990) D2 dopamine receptor gene expression by cholinergic neurons in the rat striatum. Neurosci Lett $117: 248-252$.

Le Moine C, Normand E, Bloch B (1991) Phenotypical characterization of the rat striatal neurons expressing the D1 dopamine receptor gene. Proc Natl Acad Sci USA 88:4205-4209.

Lester J, Fink S, Aronin N, DiFiglia M (1993) Colocalization of D1 and D2 dopamine receptor mRNAs in striatal neurons. Brain Res 621:106-110.

Levey A, Armstrong D, Atweh S, Terry R, Wainer B (1983) Monoclonal antibodies to choline acetyltransferase: production, specificity, and immunohistochemistry. J Neurosci 3:1-9.

Levey A, Bolam J, Rye D, Hallanger A, Demuth R, Mesulam M-M, Wainer B (1986) A light and electron microscopic procedure for double antigen localization using diaminobenzidine and benzidine dihydrochloride. J Histochem Cytochem 34:1449-1457.

Levey AI, Hersch SM, Rye DB, Sunahara RK, Niznik HB, Kitt CA, Price DL, Maggio R, Brann MR, Ciliax BJ, et al. (1993) Localization of D1 and D2 dopamine receptors in brain with subtypespecific antibodies. Proc Natl Acad Sci USA 90:8861-8865.

Malenka RC., Kocsis JD (1988) Presynaptic actions of carbachol and adenosine on corticostriatal synaptic transmission studied in vitro. J Neurosci 8:3750-3756.

McGcorge A, Faull R (1987) The organization and collatcralization of corticostriate neurones in the motor and sensory cortex of the rat brain. Brain Res 423:318-324.

McGeorge A, Faull R (1989) The organization of the projection from the cerebral cortex to the striatum in the rat. Neuroscience 29:503537.

McVittie L, Ariano M, Sibley D (1991) Characterization of anti-peptide antibodies for the localization of D2 dopamine receptors in rat striatum. Proc Natl Acad Sci USA 88:1441-1445.

Meador-Woodruff J, Mansour A (1991) Expression of the dopamine D2 receptor gene in brain. Biol Psychiatry 30:985-1007.

Meador-Woodruff JH, Mansour A, Healy DJ, Kuehn R, Zhou QY, Bunzow JR, Akil H, Civelli O, Watson SJ (1991) Comparison of the distributions of D1 and D2 dopamine receptor mRNAs in rat brain. Neuropsychopharmacology 5:231-242.

Mengod G, Martinez-Mir M, Vilaro' M, Palacios J (1989) Localiza- tion of the mRNA for the dopamine D2 receptor in the rat brain by in situ hybridization histochemistry. Proc Natl Acad Sci USA 86: $8560-8564$

Monsma F Jr, McVittie L, Gerfen C, Mahan L, Sibley D (1989) Multiple D2 dopamine receptors produced by alternative RNA splicing. Nature 342:926-929.

Morino P, Herrera MM, Meana JJ, Ungerstedt U, Hokfelt T (1992) Immunohistochemical evidence for a crossed cholecystokinin corticostriatal pathway in the rat. Neurosci Lett 148:133-136.

Nieoullon A, Cheramy A, Glowinski J (1978) Release of dopamine evoked by electrical stimulation of the motor and visual areas of the cerebral cortex in both caudate nuclei and in the substantia nigra in the cat. Brain Res 145:69-83.

Palacios J (1986) Dopamine receptor disputes. Nature 323:205.

Paxinos G, Watson C (1986) The rat brain in stereotaxic coordinates. San Diego: Academic.

Peris J, Dwoskin LP, Zahniser NR (1988) Biphasic modulation of evoked $\left[{ }^{3} \mathrm{H}\right]$ D-aspartate release by $\mathrm{D}-2$ dopamine receptors in rat striatal slices. Synapse 2:450-456.

Peters A, Palay S, Webster Hd (1976) The fine structure of the nervous system. Philadelphia: Saunders.

Romo R, Cheramy A, Godeheu G, Glowinski J (1986) In vivo presynaptic control of dopamine release in the cat caudate nucleus. III. Further evidence for the implication of corticostriatal glutamatergic neurons. Neuroscience 19:1091-1099.

Rowlands G, Roberts P (1980) Activation of dopamine receptors inhibits calcium-dependent glutamate release from cortico-striatal terminals in vitro. Eur J Pharmacol 62:239-242.

Royce GJ (1982) Laminar origin of cortical neurons which project upon the caudate nucleus: a horseradish peroxidase investigation in the cat. Exp Brain Res 205:8-29.

Schwarcz R, Creese I, Coyle J, Snyder S (1978) Dopamine receptors localized on cerebral cortical afferents to rat corpus striatum. Nature 271:766-768.

Sesack S, Aoki C, Pickel V (1994) Ultrastructural localization of D2 receptor-like immunoreactivity in midbrain dopamine neurons and their striatal targets. J Neurosci 14:88-106.

Sibley D, Jr FM (1992) Molecular biology of dopamine receptors. Trends Pharmacol Sci 13:61-69.

Somogyi P, Smith AD (1979) Projection of neostriatal spiny neurons to the substantia nigra. Application of a combined Golgi-staining and horseradish peroxidase transport procedure at both light and electron microscopy levels. Brain Res 178:3-15.

Somogyi P, Bolam JP, Smith AD (1981) Monosynaptic cortical input and local axon collaterals of identified striatonigral neurons. A light and electron microscopic study using the Golgi-peroxidase transport-degeneration procedure. J Comp Neurol 195:567-584.

Surmeier DJ, Eberwine J, Wilson CJ, Cao Y, Stefani A, Kitai ST (1992) Dopamine receptor subtypes colocalize in rat striatonigral neurons. Proc Natl Acad Sci USA 89:10178-10182.

Surmeier DJ, Reiner A, Levine M, Ariano M (1993) Are neostriatal dopamine receptors co-localized? Trends Neurosci 16:299-305.

Theodorou A, Reavill C, Jenner P, Marsden C (1981) Kainic acid lesions of striatum and decortication reduce specific $\left[{ }^{3} \mathrm{H}\right]$ sulpiride binding in rats, so D-2 receptors exist post-synaptically on corticostriate afferents and striatal neurons. J Pharmacol 33:439-444.

Towbin H, Staehelin T, Gordon J (1979) Electrophoretic transfer of proteins from polyacrylamide gels to nitrocellulose sheets: procedure and some applications. Proc Natl Acad Sci USA 76:43504354.

Webster K (1961) Cortico-striate interrelations in the albino rat. J Anat 95:532-544.

Weiner DM, Levey AI, Brann MR (1990) Expression of muscarinic acetylcholine and dopamine receptor mRNAs in rat basal ganglia. Proc Natl Acad Sci USA 87:7050-7054.

Weiner DM, Levey AI, Sunahara RK, Niznik HB, O'Dowd BF, Seeman P, Brann MR (1991) D1 and D2 dopamine receptor mRNA in rat brain. Proc Natl Acad Sci USA 88:1859-1863.

Wilson CJ (1987) Morphology and synaptic connections of crossed corticostriatal neurons in the rat. J Comp Neurol 263:567-580.

Wilson CJ, Groves PM (1980) Fine structure and synaptic connections of the common spiny neuron of the rat neostriatum: a study employing intracellular injection of horseradish peroxidase. J Comp Neurol 194:599-615.

Yamamoto BK, Davy S (1992) Dopaminergic modulation of gluta- 
mate release in striatum as measured by microdialysis. J Neurochem 58:1736-1742.

You ZB, Herrera MM, Brodin E, Meana JJ, Morino P, Hokfelt T, Silveira R, Goiny M, Ungerstedt U (1994) On the origin of striatal cholecystokinin release: studies with in vivo microdialysis. J Neurochem 62:76-85.
Yung K, Bolam J, Smith A, Hersch S, Ciliax B, Levey A (1994) Immunocytochemical localisation of D1 and D2 dopamine receptors in the basal ganglia of the rat: light and electron microscopy. Neuroscience, in press. 